\title{
Life prediction of phosphor bronze reinforcing tape used in underground power cables
}

\author{
Hang Zhou ${ }^{\mathrm{a}+}$, Sivashangari Gnanasambandam ${ }^{\mathrm{b}+}$, Maurizio Foresta ${ }^{\mathrm{a}}$, Fan Li ${ }^{\mathrm{b}}$, \\ Michelle Le Blanc ${ }^{\mathrm{b}}$, David Weston ${ }^{\mathrm{a}}$, Jingzhe Pan $^{\mathrm{a}^{*}}$ \\ ${ }^{a}$ Department of Engineering, University of Leicester, Leicester, United Kingdom LE1 7RH \\ ${ }^{b}$ Electricity Transmission Asset Management, National Grid, United Kingdom CV34 6DA
}

\begin{abstract}
:
Phosphor bronze tape is a key protection component of underground power transmission cables. During the service life, it is affected by both corrosion and fatigue effects, leading to the failure of material and eventually the failure of cables. In the present work, the combined effect on the cable failure is studied in five stages such as pit initiation, pitting corrosion control, pit to crack transfer, crack propagation control and material failure. The cable time to failure is defined as the time needed for a corrosion pit on the tap surface to transfer into a crack due to a cyclic fatigue load condition. The pit to crack transfer is described statistically by a pitting corrosion to crack propagation transfer probability function. The result shows that a life prediction model can convey the long-term data of cables and can predict the years of failure. Subsequently, life prediction model is extended and tested to include crack transfer probability function.
\end{abstract}

* Corresponding author (jp165@leicester.ac.uk).

+ Both authors contributed equally to the completion of this paper.

Keywords: tin-bronze corrosion, failure analysis, pit-crack transfer, cable life prediction, engineering asset management, corrosion fatigue, Oil-filled underground power cables 


\section{Introduction}

Underground power cables are widely used in power transmission and distribution networks because they provide reliable, safe, and incur minimum aesthetic impact. Oil-impregnated paperinsulated cables have been installed for carrying high voltages since 1960s [1]. A schematic diagram of one such cable is shown in Figure 1(a). The power transmission cable has a central oil duct inside a copper conductor which carries the load current. The conductor is insulated using successive layers of paper which are impregnated with pressurized oil in order to provide dielectric insulation. These cables generally have a lead or aluminum metallic sheath, which serves a number of purposes such as; retaining the insulating oil within the cable insulation, allowing oil pressurization, preventing the ingress of air and moisture into the insulation and providing mechanical support for the cable. The particular design of the cable considered in this paper uses a lead sheath. Due to poor creep resistance, the lead sheath is not able to hold the internal pressure alone. To overcome this limitation, phosphorbronze reinforcing tapes (tin - $0.93 \%$, phosphorus $-0.02 \%$, copper - balance) are wound over the cable's lead sheath after bitumen impregnated bedding tape has been applied. These reinforcing tapes are vital to the hydraulic security of the cable. If they are damaged the lead sheath will creep and eventually crack, leading to a fluid leak. The cable is finally given extruded PVC/PE over sheath.

A number of oil leak events have been detected over the years on cable circuits due to rupturing of the lead sheath under the oil pressure. The reason identified as the cause of these failures is the vulnerability of phosphor-bronze reinforcing tapes to corrosion $[2,3]$. The corroded reinforcing tape with the fractured face is shown in Figure 1(b). When a cable is buried underground, the external environment can interact with the tapes by slow diffusion of surrounding water into the cable, resulting 
in corrosion which can eventually lead to fracture. After the failure of the reinforcing tape, the lead sheath is not able to contain the internal pressure and leads to swelling of the sheath and thus the oil leak occurs.

Locating these leakages can be difficult, due to the migration of the oil along the outer PVC oversheath resulting in extensive civil works and extremely long outages are required to repair the cables. Meanwhile, cables are normally installed in urban areas and failures in these cables are not only expensive to repair but also have wider impacts such as transport interruption, environmental contamination, etc. Scheduled maintenance and replacement will be effective for the prevention of such cable failures in future however, this is only done at considerable effort and expense and should only occur when necessary. Hence, we need a better asset life and asset deterioration prediction methodology based on reinforcing tape corrosion that will be beneficial for both asset management and system operation.

Present study is a follow up of our previous work on pit depth distribution [4], in which the corrosion effect was simulated by applying the Monte Carlo method. The pit depth distributions on four different locations were successfully described using a Generalized Extreme Value distribution by fixing the shape factor $\xi$ and the scale factor $\varphi$, with the location factor $\mu$ being the only variable to be adjusted [4].

The aim of the present work is to model the corrosion fatigue tape failure in order to determine the exact time at which the pit growth rate changes from pitting corrosion control to crack propagation control. In the rest of the paper, pitting corrosion to crack propagation transfer will be referred to as pit-crack transfer. 
There are many models available in the literature, all originating from two basic ones which characterize the corrosion fatigue crack nucleation process: a critical pit size model $[5,6]$ and a pit growth/crack growth competition model $[7,8]$. Both the models consider corrosion pit as an equivalent surface crack and its growth rate is described by the pit kinetics. In the critical pit size model the pit grows to a critical size; a corrosion fatigue crack is considered to have nucleated from it when the local mechanical condition is adequate for the onset of the crack growth. The critical condition is defined in terms of the threshold stress intensity factor for corrosion fatigue ( $\Delta \mathrm{Kth})$ [9-11]. On the other hand, in the competition model the pit growth law of a corrosion pit is formulated using fracture mechanics. The occurrence of corrosion fatigue nucleation is defined by a critical pitting condition $(\Delta K) p$ at which the crack growth rate exceeds the pit growth rate. These two models provide a framework for predicting corrosion fatigue life by correlating fracture mechanics parameters to the crack nucleation $[7,8]$. However, the usefulness and applicability of these models are not yet fully established, because quantitative evidence is still missing.

Kondo [8] introduced the basic requirements for predicting the pit-crack transfer, consisting of two rules: first, the pit depth must reach a threshold value in order to initiate the transition. Second, at the transfer depth, the crack propagation rate is larger than the growth rate of pitting corrosion. The pitting corrosion growth rate is estimated using a basic power law, which was first introduced by Romanoff [12]. The power law model has proved to be successful in a variety of materials, for example, aluminum alloy [13-15], steel [16-18] and tin bronze in the previous work [4]. The most basic and widely applied model in crack propagation is the Paris' Law. For example, Bechhoefer et al. [19] modified the Paris' Law and applied it to life prediction on aircraft components. Researchers have also 
discussed the determination and influence of stress intensity factor $K$ on crack propagation in different materials, e.g. microcapsule-toughened epoxy [20] and aluminum alloy foams [21]. Furthermore, Pugno et al. [22] provided a complete discussion of Paris' Law and proposed a new equation to generalize it.

To monitor the total failure process of specific materials in engineering applications, some researchers proposed to combine pitting corrosion and crack propagation [10, 11, 23]. Among these works, pit-crack transfer is a crucial factor, as it influences the prediction of material life before failure. Recently, a combination of deterministic and statistical approaches was developed by Engelhardt and Macdonald [24] and applied to model the evolution of cracks in steam turbines starting from pits [25]. Similarly, Turnbull [23] developed a model based on deterministic equations with statistically distributed input parameters. The model uses Kondo's condition for the pit to crack transition and capture the statistical variability of pit and crack growth using a Monte Carlo method where input values are chosen at random from statistical distributions. It is successfully applied to the simulation of the time-evolution of the pit depth distribution and percentage of pits that transform into stress corrosion cracks for the case of steam turbine steel discs. The simulation not only reflected the trends in the experimental measurement, but also reproduced the statistical variability or noise associated with the measurements. These models are rarely tested over long term real data on corrosion fatigue life. In addition to this, Turnbull [26] used a probability theory to describe the transfer ('Transfer Probability'), suggesting that it is not always the pit with the largest depth that transfers from pitting corrosion to crack propagation. All pits with different depths have a certain probability of transfer. A cumulative distribution function (CDF) from the Weibull distribution was applied by Turnbull to 
describe this transition.

The objective of the current work is to determine the cable life based on the reinforcing tape corrosion fatigue failure. We characterized the tape corrosion fatigue failure process using the Kondo's criteria of pit to crack transition and the parameters of interest are modelled using Monte Carlo simulations. The proposed model is an integrated approach to use existing models with necessary modifications needed to predict the cable failure life of over 40 years old. Further, the present paper tests the hypothesis that the most likely pit-to-crack transfer may not happen at the largest pit, but at a pit of any size within the reasonable range.

2. Model description

Our previous work has demonstrated that the failure mechanism of phosphor bronze reinforcing tapes is corrosion fatigue, basing on stress calculation and analyzing the morphology of the cracked surfaces [3]. Typical characteristics of corrosion fatigue, such as corrosion pits on tape surface, multi- cracks in association with corrosion pits, and fatigue striation on the fractured face, are found in the failed reinforcing tape (Figure $2 \mathrm{a} \& 2 \mathrm{~b}$ ).

In the present work, a probabilistic model similar to the Turnbull model $[23,26]$ was applied to find the corrosion fatigue life of the tapes. The essential features of modelling pit growth and its transition to crack are described in details below. The structure of the methodology is shown as a flowchart in Figure 3. 


\subsection{Pit initiation}

The pit initiation is due to the electro-chemical reactions between the components of the metal material and the environment. The exact initiation mechanism is not fully understood and being continuously studied. For example, Soltis' [27] provides a summary of existing information on pit initiation. Apart from the initiation theory, the pit initiation rate is another focus, which can be seen in the work of McCafferty [28] and Cavanaugh [29]. However, compared to the total service life of the power transmission cable in [4] and the present study, the pitting initiation time is short enough to be ignored. The pitting initiation will not be considered in the total service life calculation in the present study.

\subsection{Pitting corrosion}

Pit growth is modeled using power law and also we developed a pit depth distribution model using analytical equations which are explained in detail below.

\subsubsection{Power law model for pit growth}

The next stage after pit initiation is pitting corrosion. According to Ramanoff [12] and our work [4], the pitting corrosion rate of the tin bronze tape follows the power law:

$$
x=\alpha \cdot t^{\beta}-----(1)
$$

In which $\beta$ is fixed to 0.33 , and $\alpha$ follows a Generalized Extreme Value distribution. The distribution is determined by three parameters: shape parameter $\xi$, scale parameter $\varphi$ and location parameter $\mu$. By fixing constant values of $\xi$ and $\varphi$, only changing the location parameter $\mu$, this power law can describe the pit depth distribution at a high accuracy. 


\subsubsection{Pit depth distribution model}

It is important to deduce a general expression for the pit depth distribution through the power law. It is assumed that after initiation, all pits grow continuously. The average growth rate at year $t$ is considered as the pit depth at year $t$ divided by time, i.e., we have:

$$
\text { Pit growth rate }=\frac{\text { Pit depth at year } t}{t}-----(2)
$$

The probability density function (PDF) of $\alpha$ in equation (1) is known as:

$$
G E V P D F=\frac{1}{\sigma} g(x)^{\xi+1} e^{-g(x)}------(3)
$$

Where

$$
g(x)=\left\{\begin{array}{cl}
\left(1+\left(\frac{x-\mu}{\varphi}\right) \xi\right)^{-1 / \xi} & \text { if } \xi \neq 0 \\
e^{-(x-\mu) / \varphi} & \text { if } \xi=0
\end{array}\right.
$$

For example, the pit depth distribution at the end of Year 1 is given by:

$$
P(x)=\alpha \times t^{\beta}=G E V P D F \times 1^{0.33}=G E V P D F \text { of } \alpha------(5)
$$

The above expressions are used to determine the distributions of the annual growth rate for all pits.

In the previous work [4], pit depth distributions for two failure cases at 38 years and 43 years respectively were described successfully by using the Monte Carlo simulation. In this work, the mathematical model is developed to calculate the pit depth distribution for tin bronze tape without repeatedly applying the rather time-consuming Monte Carlo simulation.

The concept of pit depth distribution is illustrated with a working example provided. In Figure 4, two curves represent the development of pit depth distribution of the same cable. The solid curve shows the pit depth distribution at the end of Year 1 and the dotted curve of Year $t$. Taking an interval of pit depth at Year 1, $[\mathrm{n}(\mathrm{n}+1)] \mu m$, the shadowed area represents the probability of occurrence of the range. 
At Year $\mathrm{t}$, the lower boundary of the range grow to $n \times t^{0.33} \mu \mathrm{m}$, the upper boundary of the range grow to $(n+1) \times t^{0.33} \mu m$, where the new shadowed area represents the probability of occurrence of the development of pit depths. Obviously, the two shadowed intervals take up the same area. This relationship can be repressed by the following equation:

$$
\int_{n}^{(n+1)}(\text { GEVPDF for } \alpha) d x=\int_{n \times t^{0.33}}^{(n+1) \times t^{0.33}}(\text { New GEVPDF at } t \text { years }) d x--(6)
$$

Applying this concept, a matrix can be written representing the probability of occurrence for all pit depth intervals. This matrix is named as 'Base Pit Depth Distribution', it represents the probability of occurrence of pits within all $1 \mu m$ of interval:

$$
\text { Base Pit Depth Distribution }=\left[\begin{array}{c}
\int_{0}^{1}(G E V P D F \text { for } \alpha) d x \\
\int_{1}^{2}(G E V P D F \text { for } \alpha) d x \\
\vdots \\
\int_{d-1}^{d}(G E V P D F \text { for } \alpha) d x \\
\int_{d}^{d+1}(G E V P D F \text { for } \alpha) d x
\end{array}\right]-----(7)
$$

Then at any time $t$ (years), the pit depth distribution matrix can be further expressed as: 
Pit Depth Distribution Matrix at $t=\left[\begin{array}{c}\left.\int_{0 / t^{0.33}}^{1 / t^{0.33}} \text { (GEVPDF for } \alpha\right) d x \\ \int_{1 / t^{0.33}}^{2 / t^{0.33}}(\text { GEVPDF for } \alpha) d x \\ \vdots \\ \int_{d-1 / t^{0.33}}^{d / 3}(\text { GEVPDF for } \alpha) d x \\ \int_{d / t^{0.33}}^{d+1 / t^{0.33}}(\text { GEVPDF for } \alpha) d x\end{array}\right]--(8)$

\subsection{Pit to crack transfer probability}

The concept of pit to crack transfer probability was first proposed by Turnbull [26], who used a cumulative distribution function of the Weibull distribution to describe the transfer probability of pitting corrosion to crack propagation. In principle, there is a probability for a pit of any depth to develop into a crack. The pit-crack transfer probability function is described as [26]:

$$
P(x)=1-e^{-(x / \lambda)^{k}}-----(9)
$$

Where $x$ is the pit depth, $\lambda$ is a scale parameter and $k$ is a shape parameter.

There is a fundamental requirement that enables a pit-crack transfer, which is the threshold pit depth. According to R.H. Jones et.al [30], the threshold pit depth can be calculated as:

$$
x_{\text {critical }}=\frac{1}{\pi}\left(\frac{\Delta K_{t h}}{F \Delta \sigma_{0}}\right)^{2}-----(10)
$$

Where $\Delta K_{t h}$ is the corrosion fatigue threshold, $\mathrm{F}$ is a constant but can be assumed as 1 if the pits are of a half-elliptical geometry, and $\Delta \sigma_{0}$ is the stress. Only the pits that surpass the threshold depth can be considered having potential to transfer in crack propagation. Finally, it is assumed that the life of the bronze tape is taken as the time for a pit to grow to the point of pit-crack transition. 


\subsection{Crack propagation}

Crack propagation starts after the pit-crack transfer, as crack propagation rate is considered much higher than pitting corrosion growth rate. The pit with the highest probability to transfer into crack is considered to be causing failure of the material. The following assumption is made for the crack growth:

\subsubsection{Crack growth rate under high mean stress}

In the literature the crack growth rate is given by $[23,26]$

$$
\frac{\mathrm{d} x}{\mathrm{~d} t}=C \Delta \sigma^{p} x^{q}-----(11)
$$

where $x$ is the crack length (for consistency with pit depth), $\Delta \sigma$ is the stress amplitude, $C$ is a constant for the same type of crack and $p=2 q \quad$ (same as for long cracks used in Linear Elastic Fracture Mechanics [23]) and $q$ are material constants. Since for the same pit depth, the pit growth rate is statistically distributed, it would be expected that the crack growth rate will also follow a similar distribution. The above equation cannot be used in the cable life prediction as the failure is dominated by the effect of mean stress.

Various empirical approaches have been proposed in the literature to address the effect of mean stress. For examples, Zhang et al. [31] suggested to modify the stress amplitude such that

$$
\Delta \sigma^{*}=\frac{\Delta \sigma}{\left[\frac{1-R}{1+R}\right]^{s}}-----(12)
$$

where $R=\frac{\sigma_{\min }}{\sigma_{\max }}$ and $s=0.5$ for copper alloys [32]. Different modifications have also been proposed by Smith, Watson and Toppers [33] proposed the effect of mean stress as a geometric mean of the maximum stress and the stress amplitude and is given below

$$
\Delta \sigma^{*}=\sqrt{\sigma_{\max } \Delta \sigma}-----(13)
$$


This approach is called SWT method and it does not depend on any material property. Walker [34] introduced an additional material property $\gamma$ in to above equations as shown in equation (14). The value of $\gamma$ ranges from 0.4 to 0.8 .

$$
\Delta \sigma^{*}=\sigma_{\max }^{1-\gamma} \Delta \sigma^{\gamma}------(14)
$$

Klesnil and Lukas [35] proposed an empirical relation to account the effect of mean stress as shown below

$$
\Delta \sigma^{*}=\frac{\Delta \sigma}{(1-R)^{\gamma}}----(15)
$$

where the value of $\gamma$ lies between 0.5 to 0.75 . We have tested all these emperical equations and concluded that none of them is valid for the cable failure. A possible reason is perhaps that the the means stress in the undergrand cable is much higher than the stress amplitude. In order to capture the cable failure observed in the field data over long term, we propose to modify equation (11) similar to the ripple loading with high mean stress and very small amplitude loading as follows

$$
\frac{\mathrm{d} x}{\mathrm{~d} t}=C\left(\Delta \sigma^{*}\right)^{p} x^{q}----(16)
$$

where $\Delta \sigma^{*}=\sigma_{\text {mean }}+\Delta \sigma$. The exponents for $\Delta \sigma$ and $x$ have been separated and we represented the effective stress as a sum of mean stress and daily alternating stress. Equation (16) can be interpreted as an empirical rate equation for crack propagation under a combination of high mean stress and small stress amplitude. Its justification is the fact that it can capture the field data collected over 30 years in this work.

The current study is based on the data collected for working cables by National Grid plc. In particular, two failure cases at two different cable locations are studied for asset management modeling. From our previous work in [4], pit depth distributions for the two failure cases provided in Table 1. 
The essential information required for the life prediction is the stresses experienced by these cables, specifically the mean stresses and the alternating stresses. The material properties and geometries of the tape and lead sheath used in calculations for the two specific cables are listed in Table 2.

Mean $\left(\sigma_{\text {mean }}\right)$ and alternating stress $(\Delta \sigma)$ are calculated as follows [3]: The reinforcing tapes experience variation in stress because of the cable internal oil pressure and temperature variation (due to variation of electricity demand with time).

$$
\begin{gathered}
\sigma_{\text {static pressure }} \cong \frac{r_{t}}{t_{t}}----(17) \\
\Delta \sigma=\sigma_{\text {dynamic pressure }}+\sigma_{\text {thermal }}----(18) \\
\sigma_{\text {thermal }} \cong \frac{\alpha_{s}^{\prime}-\alpha_{t}^{\prime}}{\frac{1}{E_{t}}+\frac{1}{E_{s}} \frac{t_{t}}{t_{s}}} \Delta T------(19)
\end{gathered}
$$

where $r_{t}$ is the radius at which the tape is wrapped around the lead sheath, $t_{t}$ is the tape thickness, $p$ is the inner pressure, $T$ is the temperature in $K, \alpha^{\prime}$ is the linear expansion coefficient, $\mathrm{E}$ is the Young modulus, $\mathrm{t}$ is the thickness, and the subscripts $\mathrm{s}$ and $\mathrm{t}$ indicate the lead sheath and the phosphor bronze tape respectively. Mean $\left(\sigma_{\text {mean }}\right)$ stress is calculated from the average of the stress exerted due to static pressure over the operating period and the $\sigma_{\text {dynamic }}$ ressure is calculated from the daily variation of stress due to static pressure. The measured calculated values of mean stresses and alternating stresses of the two failed cables are provided in Table 3.

\subsection{Procedure to calculate cable life}

The cable life of the bronze tape is defined as the time for a pit to grow to the point of pit-crack transition and is calculated by using all the above equations as shown in a schematic diagram (Flowchart ). Three stages of the method are explained in detail below. 


\subsubsection{Stage 1:Determination of pit growth parameter and analytical equation}

The pit depth distribution is modelled using the Equation 1 and the coefficients of the equations $(\beta$ and $\alpha$ ) are determined by Monte Carlo simulations [4]. The analytical form of the equation is derived using Equations 2-8.

\subsubsection{Stage 2: Optimization of pit to crack transfer}

Next step is to determine the two parameters which control the pit-crack transfer probability (CDF of Weibull distribution) of the tin bronze material as given in Equation 9. A global optimization algorithm is used with the detailed steps provided as following:

1. A combination of 2 parameters $(\lambda, k)$ determining the pit-crack transfer probability function is chosen from all the potential combinations. It is convenient to express the pit depth distribution in a matrix format with a $1 \mu m$ interval such that

$$
\text { Pit - crack transfer probability matrix }=\left[\begin{array}{c}
\int_{0}^{1}\left(1-e^{-(x / \lambda)^{k}}\right) d x \\
\int_{1}^{2}\left(1-e^{-(x / \lambda)^{k}}\right) d x \\
\vdots \\
\int_{d-1}^{d}\left(1-e^{-(x / \lambda)^{k}}\right) d x \\
\int_{d}^{d+1}\left(1-e^{-(x / \lambda)^{k}}\right) d x
\end{array}\right]--(20)
$$


2. Pit depth distributions are obtained for each working year using the model in section 2.2.2, i.e. from Year 1 to 38 for Location 1 and Year 1 to 43 for Location 2, following the individual three parameters provided in Table 1.

3. For the pit depth distribution of each working year, the pit depth distribution matrix at $\mathrm{t}$ (equation (8)) is multiplied with the pit-crack transfer probability matrix in step 1 . The products of the two equations are named as 'Failure Likelihood'. Within this step, a discriminant condition is applied from assumptions made in section 2.4. For all the 'Failure Likelihood', only the results for the pits deeper than the minimum threshold pit depth of transfer are considered.

4. For Location A, multiplying the probability matrix of each potential pit-crack transfer by the pit depth distribution matrix at Year $t_{1}\left(1 \leq t_{1} \leq 38\right)$ creates a 'Failure Likelihood' consisting 150 elements, representing pit depths intervals from [0 1] $\mu \mathrm{m}$ to [149 150] $\mu \mathrm{m}$. The largest element is considered as 'Maximum Failure Likelihood 1 Location A' at Year $t_{1}$. Of course, with $1 \leq t_{1} \leq$ 38 there are 38 'Maximum Failure Likelihood Location A' under one potential pit-crack transfer probability function. Again the largest element among these 38 is the 'Maximum Failure Likelihood 2 Location A' of this function. For Location B, under the same potential pit-crack transfer function, except the fact that there are 43 'Maximum Failure Likelihood 1 Location B' elements, due to the fact that $1 \leq t_{1} \leq 43$. The 'Maximum Failure Likelihood 2 Location B' is obtained in a same method.

5. With each potential pit-crack transfer function, a summation of the 'Maximum Failure Likelihood 2 ' is made: 
which means with all potential functions, there are equal numbers of 'Sum Maximum Likelihood 2'. The largest value among them is the final result of the optimization. The corresponding transfer pit depths, year of transfer $\left(t_{1}\right.$ and $\left.t_{2}\right)$, as well as the pit-crack transfer function are also the outcome of this analysis.

2.5.3 Stage 3: Determination of crack growth parameters (Paris law constants) and cable life

The transfer pit depth can be further used to determine parameters in Paris' Law and also to establish a life prediction model for the power transmission cables.

The relationship between the pitting corrosion growth rate and the crack propagation growth rate can be established as:

Pitting corrsoion growth rate $=V_{p}(x)=$ Crack propagation growth rate $=V_{c}(x)-(22)$

This leads to the expression of:

$$
\frac{\text { Transfer pit depth }}{\text { Year of transfer }}=C(\Delta \mathrm{k})^{m}=----
$$

where $\mathrm{C}$ and $\mathrm{m}$ are Paris Law constants. The above equation is used to calculate the cable life given the Paris law constants.

3. Results and discussions

Pit depth distribution of the reinforcing tape is the starting point to calculate the life of the power cable. 
First the simulated pit depth distribution is modelled with an analytical equation and used to calculate the pit to crack transfer probability. Then, Paris constants are calculated to predict the cable life.

\subsection{Pit growth modelling}

Pit depth distribution is modelled using power law (Equation 1) as detailed in our previous work [4] using Monte Carlo simulations. The analytical equation for the pit depth distribution is derived using equations 2-8.

To validate the analytical method, data from a working cable is used for comparison between the mathematical analytical pit depth distribution model and the Monte Carlo simulation method. Shown in Figure 5, red curved represent the Monte Carlo method, under simulation of 100 pits, which is relatively small number, both models appear to have a similar shape, but still with various differences. When increasing the simulation pit number to 1 million, as shown in Figure 6 , there is basically no difference observed between two models, which proved the validity of the model.

\subsection{Pit to crack transfer}

A relationship between the pit growth speed and the crack propagation speed is shown in Figure 7. Pit to crack transfer is calculated using Equation 9. Optimization procedure is done to calculate the two parameters ( $\lambda$ and $\mathrm{k})$ used in the equation. The boundary condition is required to do the simulation and the derived parameters are explained below.

\subsubsection{Boundary conditions for pit-crack transfer probability function}

The thickness of the tin bronze tape is $150 \mu \mathrm{m}$. A pit depth of $150 \mu \mathrm{m}$ is therefore the maximum limit. Moreover, any transfer function (Weibull CDF) reaching $100 \%$ when pit depth $x<150 \mu m$ is considered as invalid. This is regarded as the upper boundary of the transfer function. The lower 
boundary of the transfer function is determined by the threshold pit depth for both locations. As previously mentioned in section 2.3 , the only unknown information is the threshold of the stress intensity factor. However, according to Kunz and Collini [36], there are results obtained for threshold stress intensity factors of coarse grain (CG) copper and Annealed CG copper. The results rely on the R-ratio, which is the ratio of the minimum value of cyclic stress and the maximum value of the cyclic stress. In the case of Location A, $R_{1}=0.9856$ and for Location $\mathrm{B}, R_{2}=0.9719$. For the results of these two R-ratios, it can be estimated that the threshold intensity factor can be as low as $1.5 \mathrm{MPa} \sqrt{\mathrm{m}}$. Applying this threshold intensity factor value to equation (10), it is estimated that the initial threshold pit depth for Location A is $35 \mu \mathrm{m}$ and the threshold pit depth for Location B is $60 \mu \mathrm{m}$. These two values are used to select the valid $(\lambda, k)$ combinations from all initial choices of $\lambda$ and $k$ combinations. A representative curve of pit-crack transfer probability is shown in Figure 8 . The application of the above boundary conditions is considered as a pre-selection step, the purpose is to accelerate the optimization. If there is no such step, the amount of equations that are involved in optimization can be observed from Figure 9. To describe the boundary conditions in more details, two conditions have to be fulfilled regarding the threshold pit depths for two locations: 1 . The probability of transfer is 0 at pit depth of $35 \mu \mathrm{m}$. 2. The probability of transfer is larger than 0 start from pit depth of $60 \mu \mathrm{m}$. A range of the potential pit to crack transfer curves can be seen in Figure 10.

\subsubsection{Parameters $(\lambda, k)$ for pit-crack transfer probability function}

From section 2.5 , one of the final results of the optimization algorithm is parameters $(\lambda, k)$ in the transfer function. With the current data, the simulation result is $(\lambda, k)=(109.3,6.1)$. A plot of the determined transfer function using these two parameters is shown in Figure 11. The mathematical 
expression for this pit-crack transfer probability function is therefore given by:

$$
P(x)=1-e^{-(x / 109.3)^{6.1}}------(22)
$$

\subsubsection{Transfer pit depths for both locations}

The transfer pit depth for cables at Location A is $113 \mu \mathrm{m}$ and the transfer pit depth for cables at Location B is $111 \mu m$.

\subsection{Determination of crack growth (Paris Law) parameters}

With the simulation results mentioned above, the relationships between the pitting corrosion growth rate and the crack propagation growth rate can be established according to a general expression given in equation 23. The shape factor $Y$ was taken as 1 to be on the safe side. By the nature of Paris' Law, it can be assumed that $p=2 q$, which gives the parameters of the modified Paris' Law as: $C=$ $0.108, p=0.453, q=0.226$.

This gives the final expression of Paris' Law as:

$$
V_{c}(x)=0.108 \times\left(\sigma_{\text {mean }}+\Delta \sigma\right)^{0.453} \times x_{\text {transfer }}^{0.226}------(25)
$$

In this expression the pit depth is given in the unit of $\mu m$, time in the unit of years, and stress in the unit of MPa.

\subsection{Cable life prediction}

The above key parameters such as pit growth parameters, pit to crack parameters and transfer depth are critical to life prediction of power transmission cables. To calculate life of any working cable, the first step is to simulate the pit depth distribution on the surface of tin 
bronze tape by method developed in [4]. The result is a combination of three parameters $\left(\sigma_{\text {sample }}, \mu_{\text {sample }}, k_{\text {sample }}\right)$ which governs the GEV distribution. In the second step, upon obtaining the three governing parameters, a pit depth distribution of any year can be obtained using the model described in section 2.2. In the third step, multiplying the pit depth distribution with the determined pit-crack transfer function, the transfer pit depth of the sample can be obtained, naming it $x_{\text {transfer }}$. From equation (25), the cable life prediction function can be written as:

$$
t_{\text {cable }}=\frac{x_{\text {transfer }}^{0.774}}{0.108 \times\left(\sigma_{\text {mean }}+\Delta \sigma\right)^{0.453}}---(26)
$$

\subsection{Validation of life prediction model on existing circuit}

The life prediction model is applied to 10 existing cables to validate the accuracy of prediction. In Table 4, the key parameters for determining pit depth distribution are given, which from the previous results, are a variety of location parameters $\mu$ for the GEV distribution. With the location parameters $\mu$, the corresponding pit-crack transfer pit depths are also given in Table 4.

The prediction years can be interpreted as a relative failure probability comparing to the solid failure cases. In such concept, for different cable sections showing from Figure 12 to Figure 21 are also the failure probabilities relative to the failed section probabilities. The closer a prediction year of certain section is to the failed section, the higher probability of failure this specific section has. From Figure 12 to Figure 21, the prediction year at which $P_{\text {failure }}=P_{\text {failure at calibration }}$ of cable sections are shown in the scatter plot format for all 
10 locations. The cable data were referenced to the current year of 2017. A few known conditions of the cable sections are taken for the validation of the proposed life prediction model:

- Section 46 of Location 1 was known corroded, according to the model the predicted year is 2012, which falls below the referencing line of 2017. See Figure 12.

- Section 46 and Section 61 of Location 2 were decommissioned, the predicted years are 2015 and 2009, Section 65 of Location 2 were known failure, the predicted year is 2009, which falls below the referencing line of 2017. See Figure 13.

- Section 93 of Location 4 was decommissioned, the predicted year is 2015, which falls below the referencing line of 2017. See Figure 15.

- Section 176 of Location 5 was known failure, the predicted year is 2016, which falls below the referencing line of 2017. See Figure 16.

- Section 108 of Location 6 was known corroded, the predicted year is 2014, which falls below the referencing line of 2017. See Figure 17.

- Section 2 and Section 54 of Location 7 were known corroded, the predicted years for the two sections are 2011 and 2010, which falls below the referencing line of 2017. See Figure 18.

From the above information, the results can be considered as providing relatively accurate predictions with 'positive error'. One would want the model to predict failures when there are failures and should not predict success when there are failures. Such a 'positive error' is tolerable from a safety point of view. However, if the model predicts failure and no failure 
has occurred, then the negative error can be expensive because of unnecessary repairs, but it is not unsafe.

\section{Conclusion}

In summary, this paper provided a further study on the entire failure process of the phosphor bronze tape in underground power transmission cables. Following an accurate Monte Carlo simulation on pit depth distributions, a probability description of pitting corrosion to crack propagation probability transfer function is introduced in this study.

- A pit depth distribution model is developed. Combined with the author's previous research results on pit depth distribution on specific years [4], this study provides a model that can describe pit depth distribution on any time in request.

- An equation of the crack propagation in reinforced tin-bronze tape is given, under the assumption of a high mean stress and a relatively low alternating stress. For which all parameters are fixed numerically.

- A function of the pitting corrosion to crack propagation probability is given using the cumulative distribution function of the Weibull distribution, with all parameters are fixed numerically.

- A proposal for applying this 'Pit initiation $\rightarrow$ Pitting Corrosion $\rightarrow$ Pit crack transfer $\rightarrow$ Crack propagation $\rightarrow$ Failure' whole process analysis to the prediction of underground power transmission cable service life is raised. 


\section{Acknowledgements:}

This project was funded by Network Innovation Allowance (Project number: NIA_NGET0103) which is greatly acknowledged. Hang Zhou acknowledges financial supports for his $\mathrm{PhD}$ study by the Great Britain-China Educational Trust (GBCET) and the Henry Lester Trust Ltd. This research used the ALICE High Performance Computing Facility at the University of Leicester. 
References:

1. Grid, N., Undergrounding high voltage electricity transmission lines. 2015, Warwick.

2. Kingerley, D.G. and M.J. Longster, Stress corrosion of phosphor-bronze reinforcing tapes on underground power cables. Corros. Sci., 1974. 14(2): p. 165-167.

3. Maurizio, F., et al., Corrosion fatigue of phosphor - bronze reinforcing tapes on underground power transmission cables - Failure analysis. Submitted to Engineering Failure Analysis.

4. Zhou, H., et al., Measurement and Modeling of Pitting Depth Distribution for Phosphor Bronze Tapes Used in Underground Power Transmission Cables. CORROSION, 2017. 73(7): p. 844852.

5. Hoeppner, D.W., Model for prediction of fatigue lives based upon a pitting corrosion fatigue process, in Fatigue Mechanisms, J.T. Fong, Editor. 1979, ASTM STP675: Philadelphia PA. p. 841.

6. Müller, M., Theoretical Considerations on Corrosion Fatigue Crack Initiation. Metall. Trans. , 1982. 13A(4): p. 649-655.

7. Y.Kondo and R.P.Wei, Proceedings of EVALMAT89. Approach on quantitative evaluation of corrosion fatigue crack initiation condition. 1989, Kobe, Japan: Iron \& Steel Institute of Japan.

8. Y.Kondo, Prediction of Fatigue Crack Initiation Life Based on Pit Growth. Corrosion Science, 1989. 45(1): p. 7-13.

9. Amiri, M., et al., A continuum damage mechanics model for pit-to-crack transition in AA2024-

T3. Corrosion Science, 2015. 98: p. 678-687.

10. Rokhlin, S.I., et al., Effect of pitting corrosion on fatigue crack initiation and fatigue life. Engineering Fracture Mechanics, 1999. 62(4-5): p. 425-444.

11. Xie, C., et al., Corrosion Reliability Analysis Considering the Coupled Effect of Mechanical Stresses. ASCE-ASME Journal of Risk and Uncertainty in Engineering Systems, Part B: Mechanical Engineering, 2016. 2(3): p. 031001-031001.

12. M.Romanoff, Underground corrosion. NBS Circular 579, National Bureau of Standard, Washington, DC, 1957. 
13. D.G.Harlow and R.P.Wei, Probability approach for prediction of corrosion and corrosion fatigue life. AIAA JOURNAL, 1994. 32(10): p. 2073-2078.

14. D.G.Harlow and R.P.Wei, A probability model for the growth of corrosion pits in aluminum alloys induced by constituent particles. Engineering Fracture Mechanics, 1998. 59(3): p. 305325.

15. J.Rajasankar and N.R.Iyer, A probability-based model for growth of corrosion pits in aluminium alloys. Engineering Fracture Mechanics, 2006. 73: p. 553-570.

16. F.Caleyo, et al., Probability distribution of pitting corrosion depth and rate in underground pipelines: a Monte Carlo study. Corrosion Science, 2009. 51: p. 10.

17. J.L.Alamilla and E.Sosa, Stochastic modelling of corrosion damage propagation in active sites from field inspection data. Corrosion Science, 2008. 50(7): p. 9.

18. M.Chookah, M.Nuhi, and M.Modarres, A probabilitistic physics-of-failure model for prognostic health management of strucutres subjuect to pitting and corrosion-fatigue. Reliability Engineering and System Safety, 2011. 96: p. 10.

19. Bechhoefer, E., A.P.F. Bernhard, and D. He, Use of Paris Law for Prediction of Component Remaining Life. Conference Paper in IEEE Aerospace Conference Proceedings, 2008: p. 8.

20. Brown, E.N., S.R. White, and N.R. Sottos, Fatigue crack propagation in microcapsuletoughened epoxy. J Mater Sci 2006. 41: p. 8.

21. Olurin, O.B., et al., Fatigue crack propagation in aluminium alloy foams. International Journal of Fatigue, 2001. 23: p. 8.

22. Pugno, N., et al., A generalized Paris' law for fatigue crack growth. Journal of the Mechanics and Physics of Solids, 2006. 54: p. 17.

23. Turnbull, A., L.N. McCartney, and S. Zhou, A model to predict the evolution of pitting corrosion and the pit-to-crack transition incorporating statistically distributed input parameters. Corrosion Science, 2006. 48(8): p. 2084-2105.

24. Engelhardt, G. and D.D. Macdonald, Unification of the deterministic and statistical approaches for predicting localized corrosion damage. I. Theoretical foundation. Corros. Sci., 2004. 46(11): p. 2755-2780. 
25. G. Engelhardt, et al., Deterministic Prediction of Corrosion Damage in Low Pressure Steam Turbines Power Plant Chem., 2004. 6(11): p. 647.

26. Turnbull, A. and S. Zhou, Pit to crack transition in stress corrosion cracking of a steam turbine disc steel. Corrosion Science, 2004. 46(5): p. 1239-1264.

27. Soltis, J., Passivity breakdown, pit initiation and propagation of pits in metallic materials Review. Corrosion Science, 2015. 90: p. 5-22.

28. McCafferty, E., Pit Initiation on Aluminum as a Queueing Process. J. Electrochem. Soc., 2010. 157(11): p. 6.

29. Cavanaugh, M.K., N. Birbilis, and R.G. Buchheit, Modeling pit initiation rate as a function of environment for Aluminum alloy 7075-T651. Electrochimica Acta, 2012. 59: p. 336-345.

30. R.H.Jones and R.E.Ricker, Mechanisms of Stress-Corrosion Cracking, in Stress-Corrosion Cracking Materials Performance and Evaluation, R. H.Jones, Editor. 1992, ASM International. p. $1-40$.

31. Zhang, J., X.D. He, and S.Y. Du, A simple engineering approach in the prediction of the effect of stress ratio on fatigue threshold. International Journal of Fatigue, 2003. 25(9): p. 935-938.

32. Taylor, D., A Compendium of Fatigue Thresholds and Growth Rates. 1985: Engineering Materials Advisory Services Limited.

33. Smith, K., T. Topper, and P. Watson, A stress-strain function for the fatigue of metals(Stressstrain function for metal fatigue including mean stress effect). Journal of materials, 1970. 5: p. 767-778.

34. Walker, K., The effect of stress ratio during crack propagation and fatigue for 2024-T3 and 7075-T6 aluminum, in Effects of environment and complex load history on fatigue life. 1970, ASTM International.

35. Klesnil, M. and P. Lukáš, Effect of stress cycle asymmetry on fatigue crack growth. Materials Science and Engineering, 1972. 9: p. 231-240.

36. Kunz, L. and L. Collini, Mechanical properties of copper processed by Equal Channel Angular Pressing - a review. Frattura ed Integrità Strutturale, 2012. 19: p. 15. 
List of Tables:

Table 1: Basic information of samples from Location A and Location B

Table 2: Material properties and geometry of the tape and lead sheath

Table 3: Measured stress values at failure conditions

Table 4: Location parameter $\mu$ for cables and corresponding transfer pit depths 
Table 1: Basic information of samples from Location A and Location B

\begin{tabular}{|c|c|c|}
\hline Sample Label & Year of Failure & Pit Depth Distribution Parameter \\
\hline Location A & 38 & $\varphi=0.5, \mu=3.4, k=0.5$ \\
\hline Location B & 43 & $\varphi=0.5, \mu=4.7, k=0.5$ \\
\hline
\end{tabular}


Table 2: Material properties and geometry of the tape and lead sheath

\begin{tabular}{|c|c|c|c|c|}
\hline & $\mathrm{E}[\mathrm{GPa}]$ & $\alpha^{\prime}\left[10^{-5} \mathrm{~K}^{-1}\right]$ & $\mathrm{t}[\mathrm{mm}]$ & $\mathrm{r}[\mathrm{mm}]$ \\
\hline Phosphor bronze tape & 110 & 1.66 & 0.1524 & 49.276 \\
\hline Lead sheath & 16 & 2.8 & 3.175 & 48.768 \\
\hline
\end{tabular}


Table 3: Measured stress values at failure conditions

\begin{tabular}{|c|c|c|c|c|c|}
\hline Location & $\sigma_{\text {thermal }}(\mathrm{MPa})$ & $\sigma_{\text {dynamic }}(\mathrm{MPa})$ & Time (years) & $\sigma_{\text {mean }}(\mathrm{MPa})$ & $\Delta \sigma(\mathrm{MPa})$ \\
\hline A & 0.4 & 0.6 & 38 & 141.9 & 1.03 \\
\hline B & 2 & 3.37 & 43 & 104 & 1.48 \\
\hline
\end{tabular}


Table 4: Location parameter $\mu$ for cables and corresponding transfer pit depths

\begin{tabular}{|c|c|c|}
\hline Location & Pit depth distribution parameters & Transfer pit depth $(\boldsymbol{\mu m})$ \\
\hline Location 1 & $\varphi=0.5, \mu=3.0, k=0.5$ & 114 \\
\hline Location 2 & $\varphi=0.5, \mu=2.2, k=0.5$ & 115 \\
\hline Location 3 & $\varphi=0.5, \mu=1.0, k=0.5$ & 115 \\
\hline Location 4 & $\varphi=0.5, \mu=3.0, k=0.5$ & 114 \\
\hline Location 5 & $\varphi=0.5, \mu=2.8, k=0.5$ & 114 \\
\hline Location 6 & $\varphi=0.5, \mu=1.8, k=0.5$ & 115 \\
\hline Location 7 & $\varphi=0.5, \mu=1.0, k=0.5$ & 115 \\
\hline Location 8 & $\varphi=0.5, \mu=1.0, k=0.5$ & 115 \\
\hline Location 9 & $\varphi=0.5, \mu=1.0, k=0.5$ & 115 \\
\hline Location 10 & $\varphi=0.5, \mu=2.0, k=0.5$ & 115 \\
\hline
\end{tabular}




\section{List of Figures:}

Figure 1: (a) A schematic diagram of cross section of the oil filled underground power cable (b) Corroded reinforcing phosphor bronze tape surface with a fracture end on the left (thickness of the tape $150 \mu \mathrm{m})$.

Figure 2: (a) 3D optical microscopy image showing pits on the outer surface of the tape

(b) SEM image of corrosion fatigue crack starting from a pit [3]. The crack in the cross section shown was normal to the direction of the applied load (longitudinal axis of the tape).

Figure 3: Pictorial representation for the structure of the paper

Figure 4: Example plot for time related pit depth distribution calculation

Figure 5: Theoretical pit depth distribution with time model comparing to Monte Carlo simulation pit depth distribution model with an initial pit number of 100

Figure 6: Theoretical pit depth distribution with time model comparing to Monte Carlo simulation pit depth distribution model with an initial pit number of 1 million

Figure 7: two stages of failure case where pitting corrosion transfers into crack propagation

Figure 8: A representative curve among all the potential pit to crack transfer probability functions (Cumulative distribution function of the Weibull distribution)

Figure 9: Potential pit to crack transfer probability functions represented in Weibull CDF plots

Figure 10: Possible transfer curves

Figure 11: Determined pit to crack transfer probability function plot

Figure 12: Validation of life prediction model by prediction year at which $P_{\text {failure }}=$ $P_{\text {failure at calibration }}$ of different cable sections at Location 1 
Figure 13: Validation of life prediction model by prediction year at which $P_{\text {failure }}=$ $P_{\text {failure at calibration }}$ of different cable sections at Location 2

Figure 14: Validation of life prediction model by prediction year at which $P_{\text {failure }}=$ $P_{\text {failure at calibration }}$ of different cable sections at Location 3

Figure 15: Validation of life prediction model by prediction year at which $P_{\text {failure }}=$ $P_{\text {failure at calibration }}$ of different cable sections at Location 4

Figure 16: Validation of life prediction model by prediction year at which $P_{\text {failure }}=$ $P_{\text {failure at calibration }}$ of different cable sections at Location 5

Figure 17: Validation of life prediction model by prediction year at which $P_{\text {failure }}=$ $P_{\text {failure at calibration }}$ of different cable sections at Location 6

Figure 18: Validation of life prediction model by prediction year at which $P_{\text {failure }}=$ $P_{\text {failure at calibration }}$ of different cable sections at Location 7

Figure 19: Validation of life prediction model by prediction year at which $P_{\text {failure }}=$ $P_{\text {failure at calibration }}$ of different cable sections at Location 8

Figure 20: Validation of life prediction model by prediction year at which $P_{\text {failure }}=$ $P_{\text {failure at calibration }}$ of different cable sections at Location 9

Figure 21: Validation of life prediction model by prediction year at which $P_{\text {failure }}=$ $P_{\text {failure at calibration }}$ of different cable sections at Location 10 


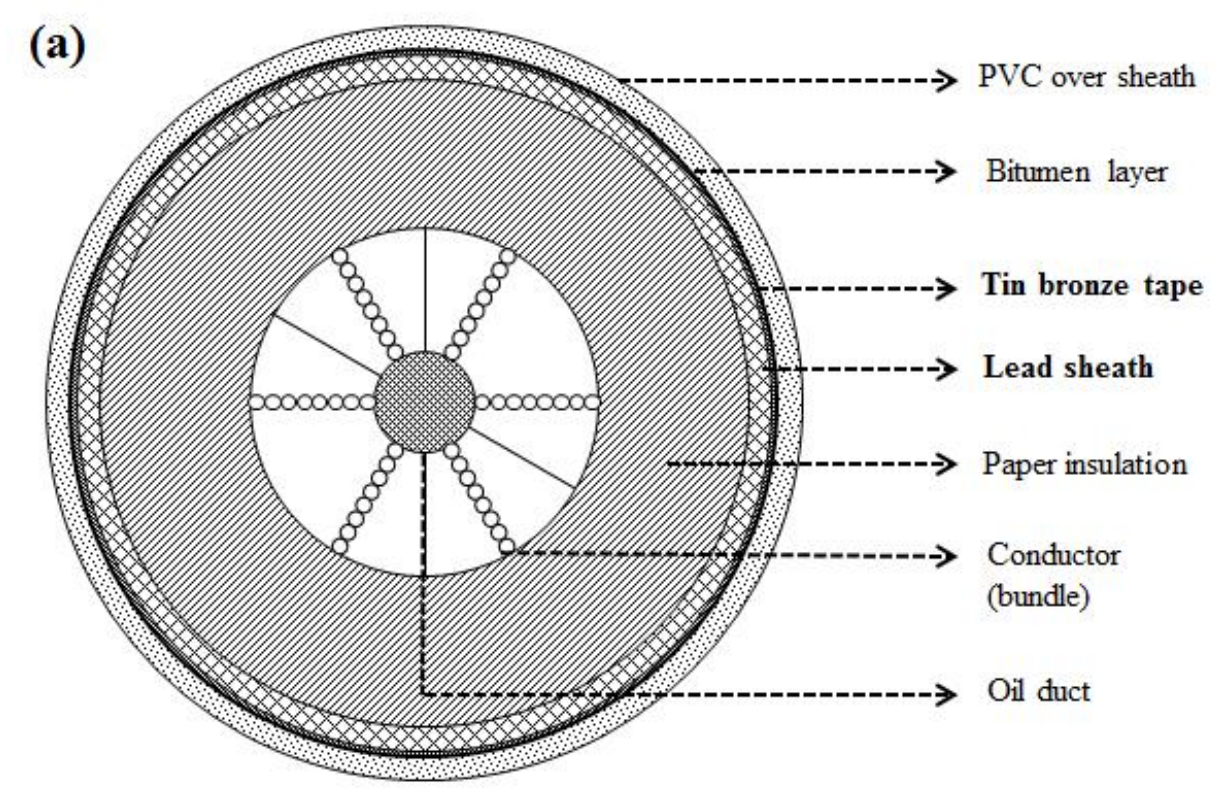

(b)

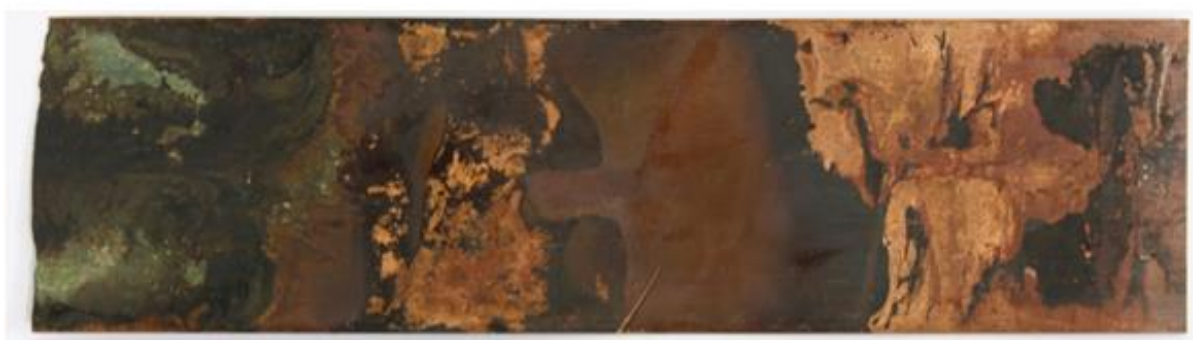

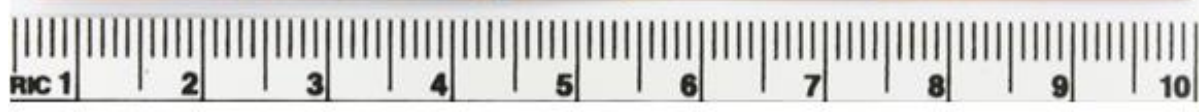

Figure 1: (a) A schematic diagram of cross section of the oil filled underground power cable

(b) Corroded reinforcing phosphor bronze tape surface with a fracture end on the left (thickness of the tape $150 \mu \mathrm{m}$ ). 

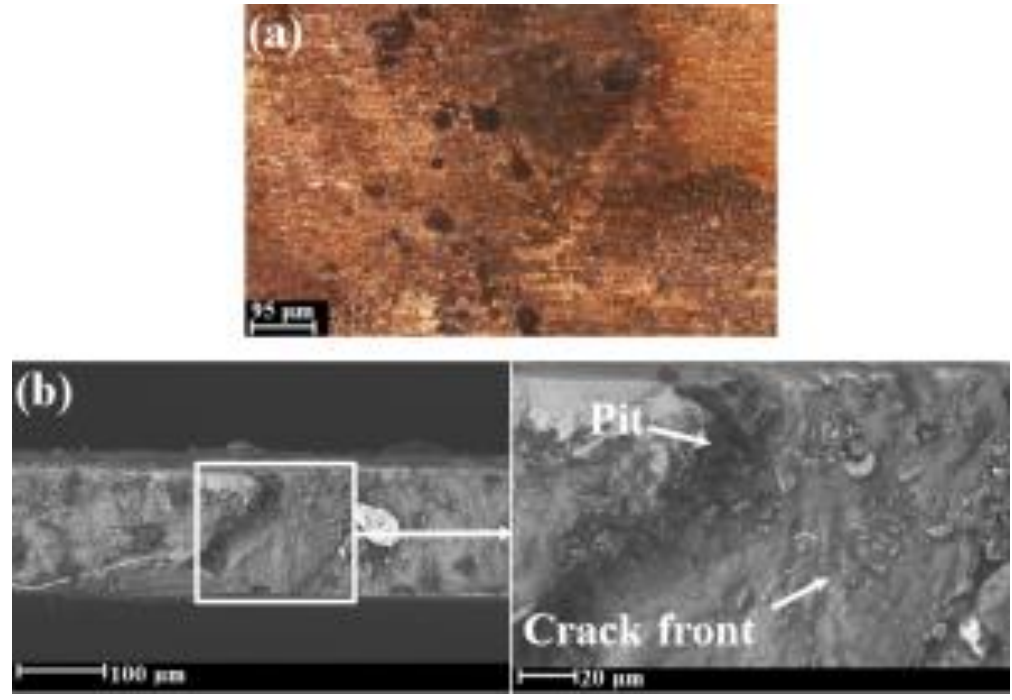

Figure 2: (a) 3D optical microscopy image showing pits on the outer surface of the tape

(b) SEM image of corrosion fatigue crack starting from a pit [3]. The crack in the cross section shown was normal to the direction of the applied load (longitudinal axis of the tape). 


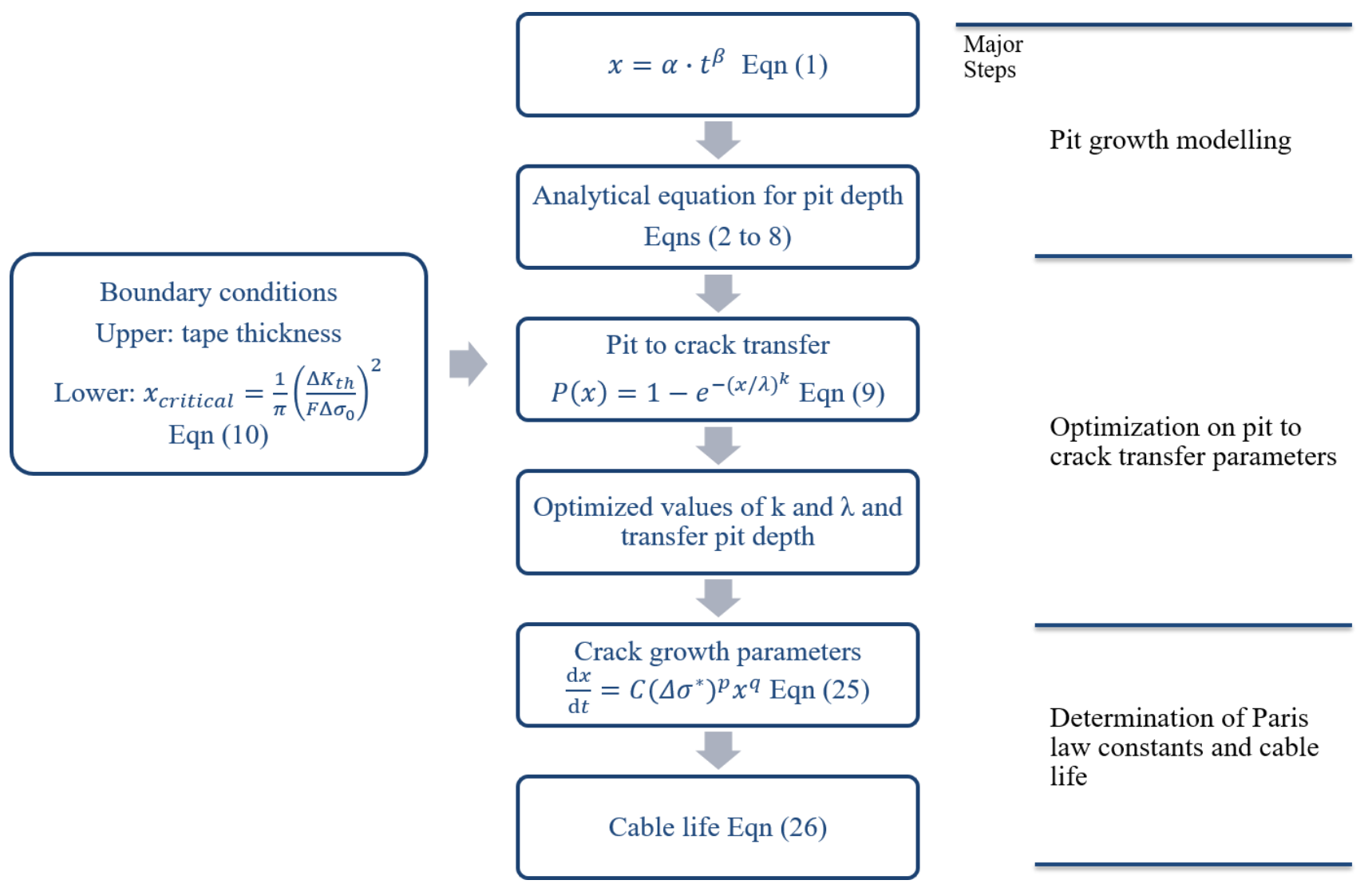

Figure 3: Pictorial representation for the structure of the paper 


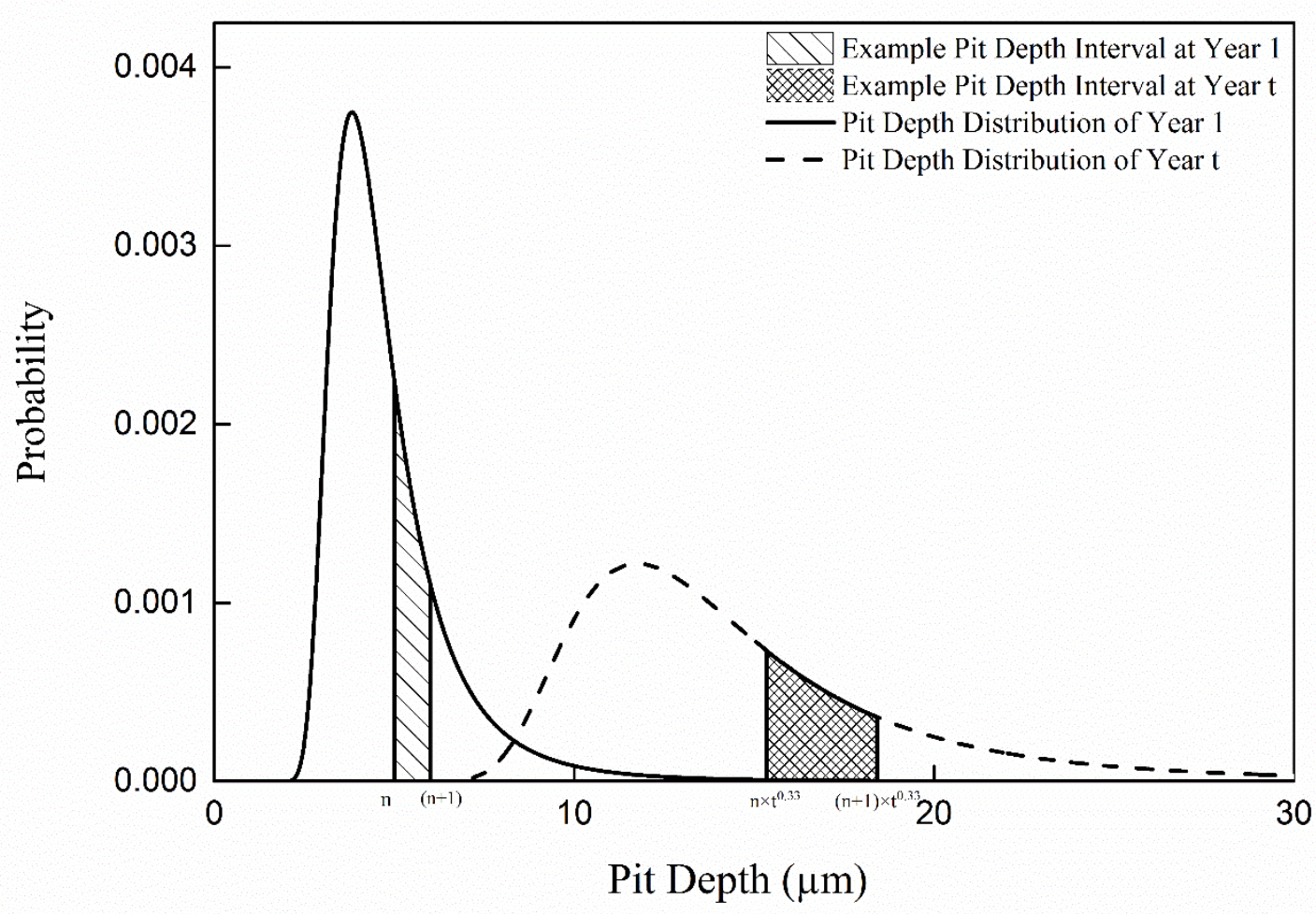

Figure 4: Example plot for time related pit depth distribution calculation 

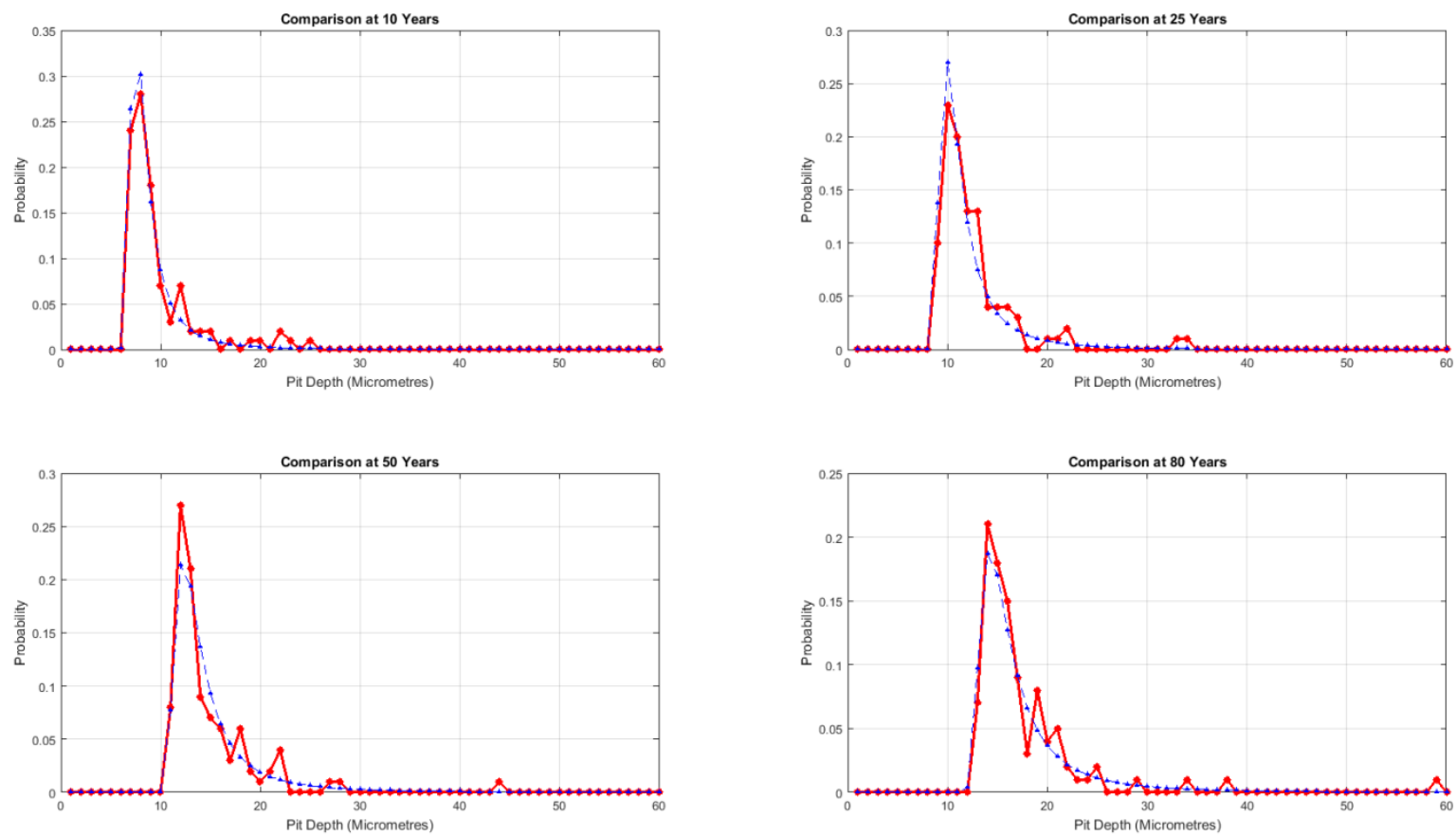

Figure 5: Theoretical pit depth distribution with time model comparing to Monte Carlo simulation pit depth distribution model with an initial pit number of 100 

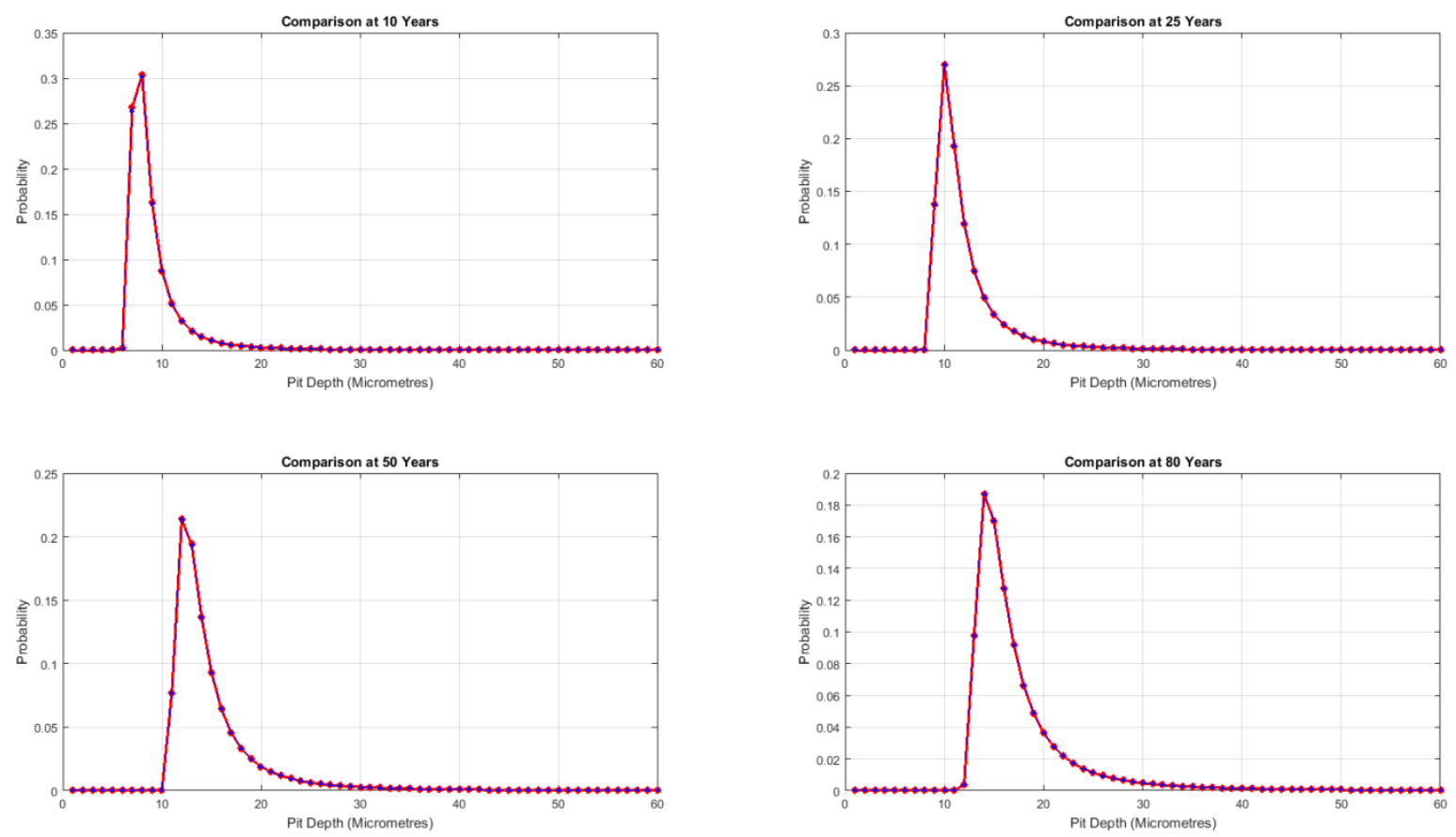

Figure 6: Theoretical pit depth distribution with time model comparing to Monte Carlo simulation pit depth distribution model with an initial pit number of 1 million 


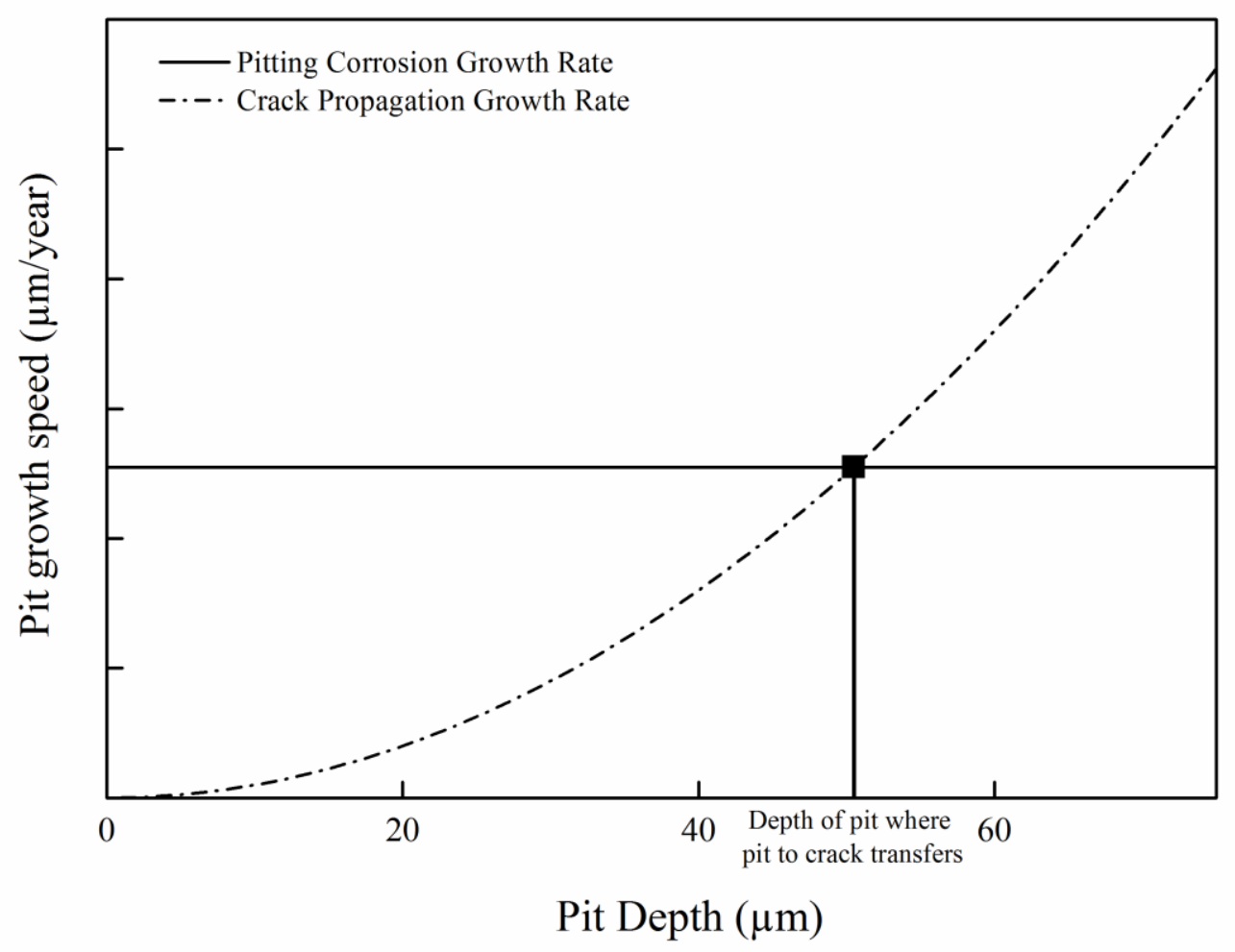

Figure 7: Two stages of failure case where pitting corrosion transfers into crack propagation 


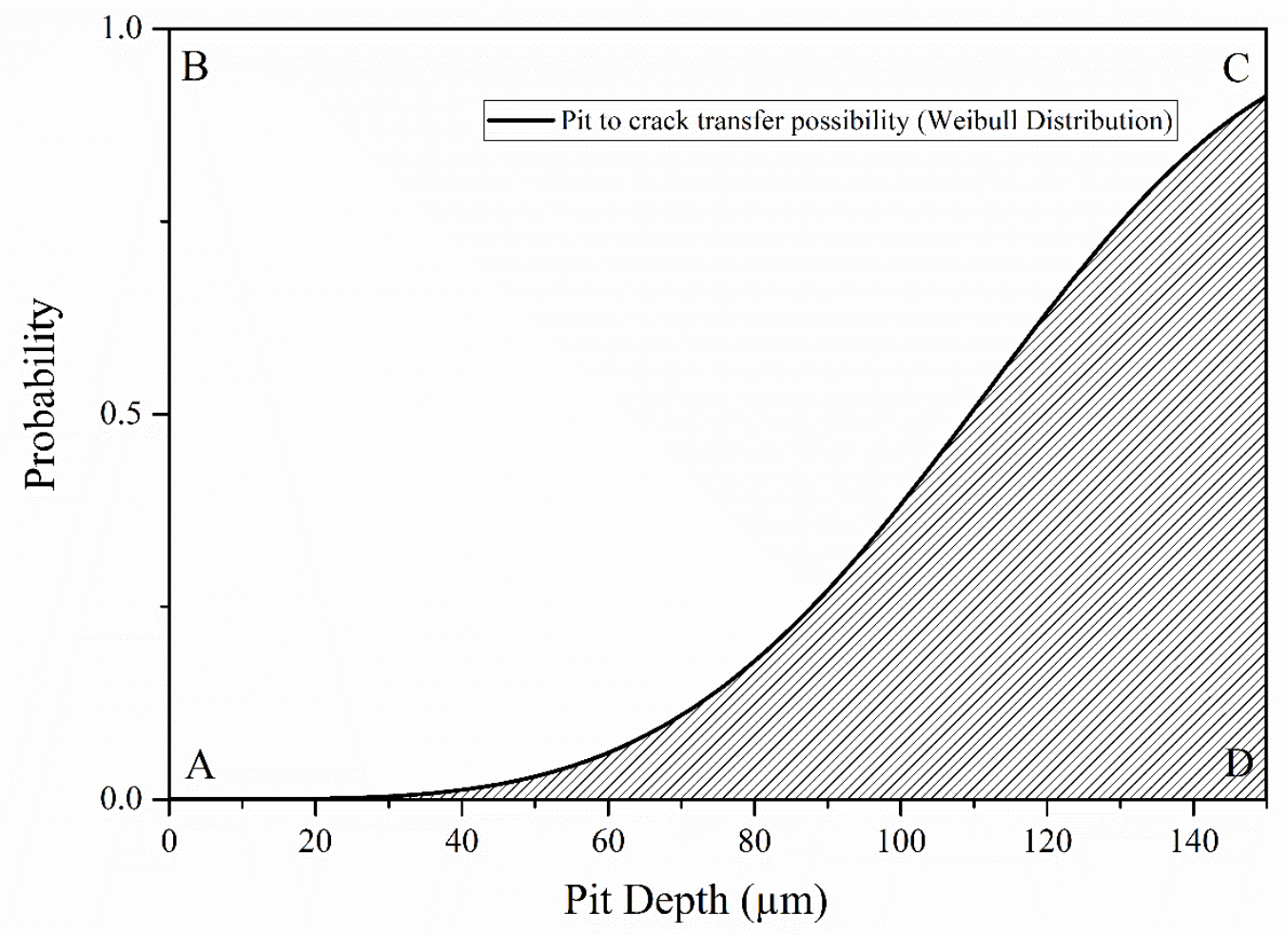

Figure 8: A representative curve among all the potential pit to crack transfer probability functions (Cumulative distribution function of the Weibull distribution) 


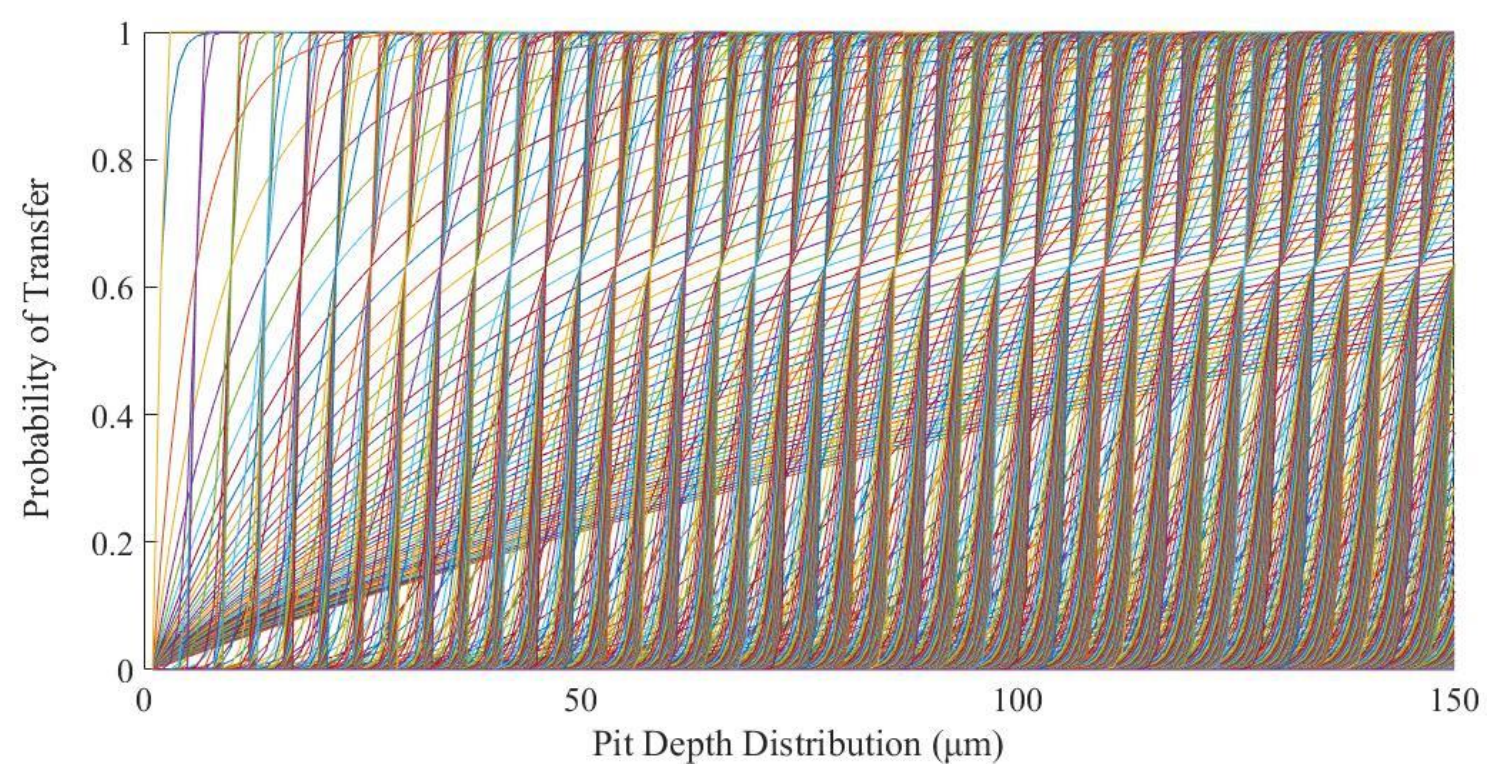

Figure 9: Potential pit to crack transfer probability functions represented in Weibull CDF plots 


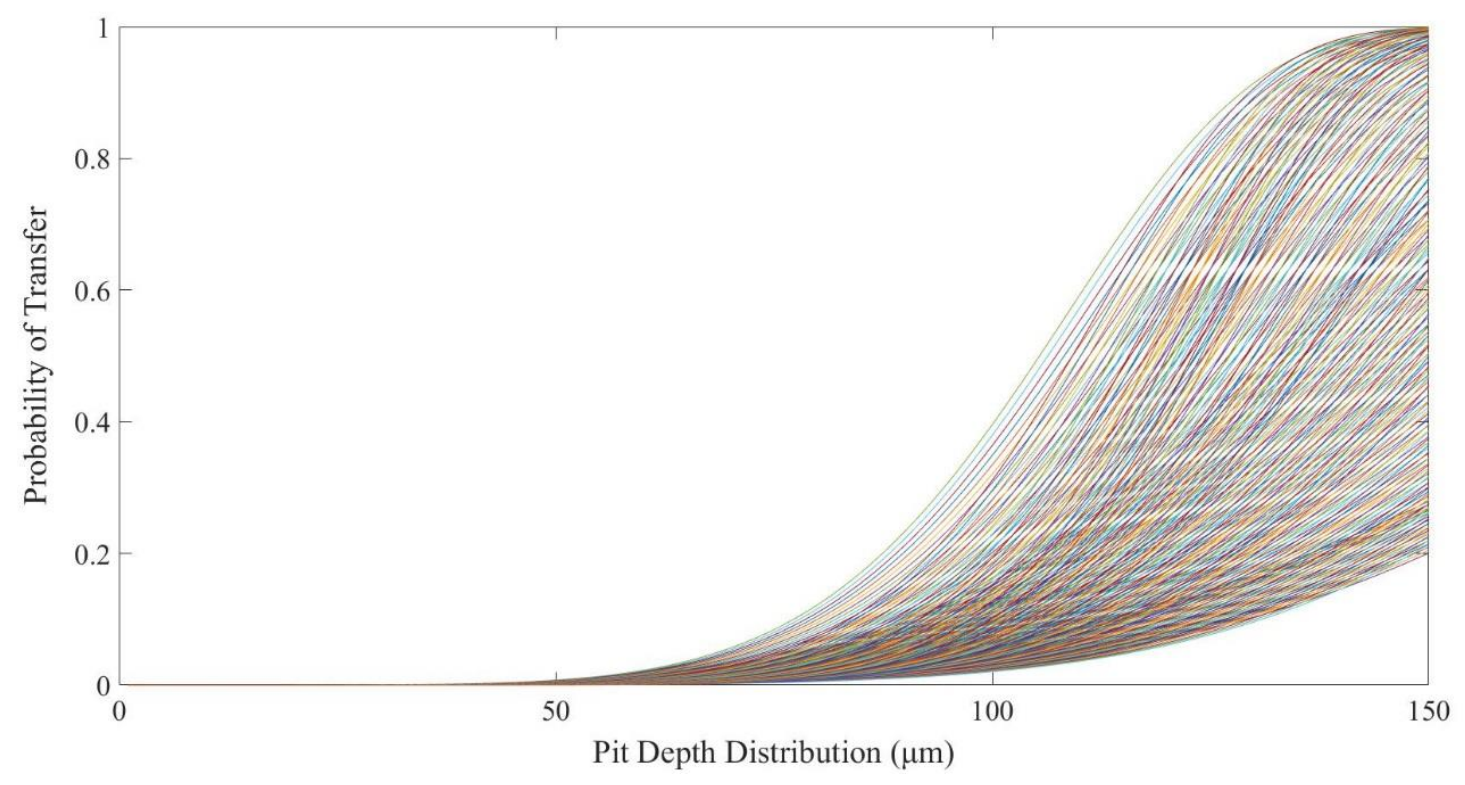

Figure 10: Possible transfer curves 


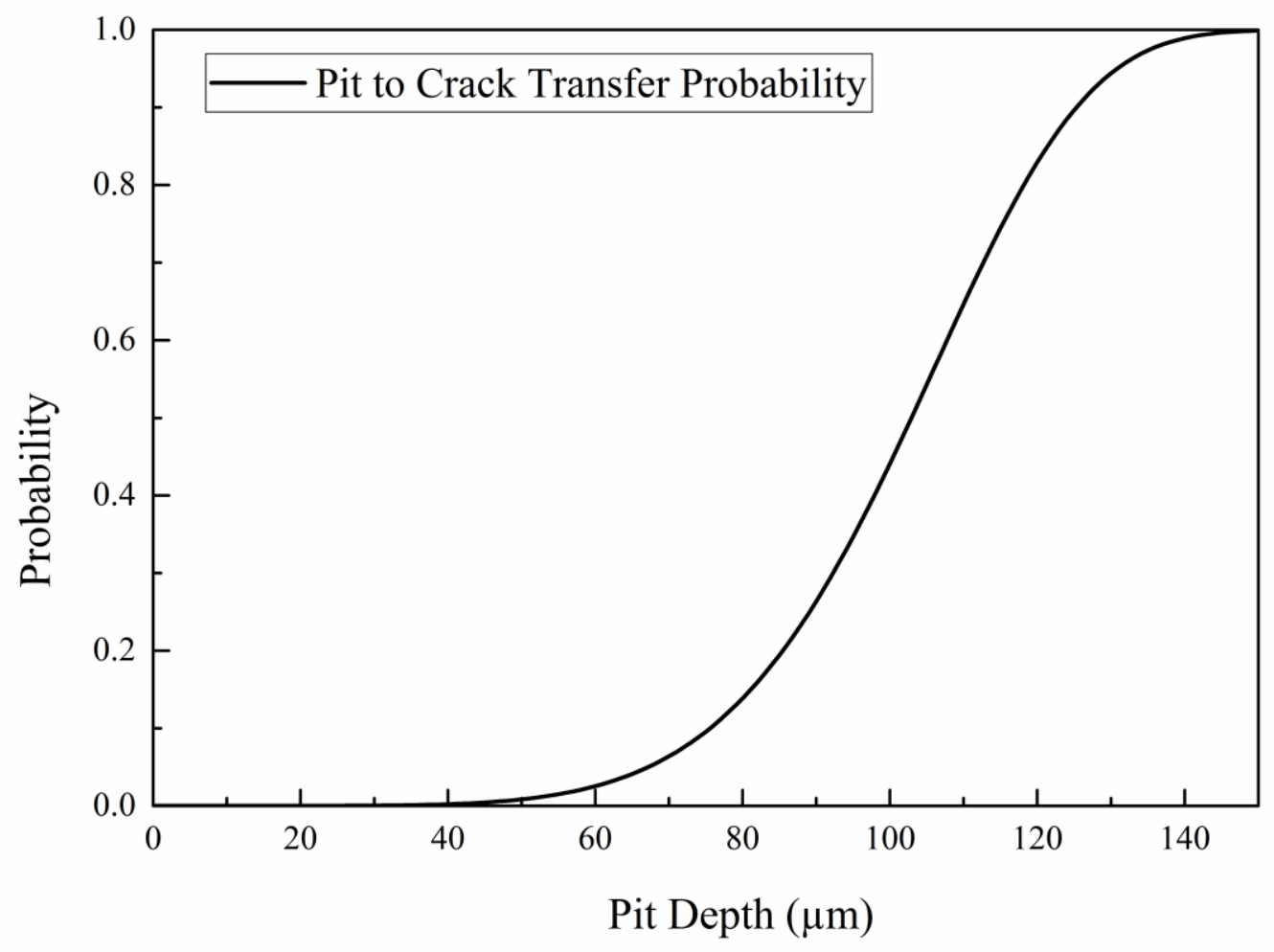

Figure 11: Determined pit to crack transfer probability function plot 


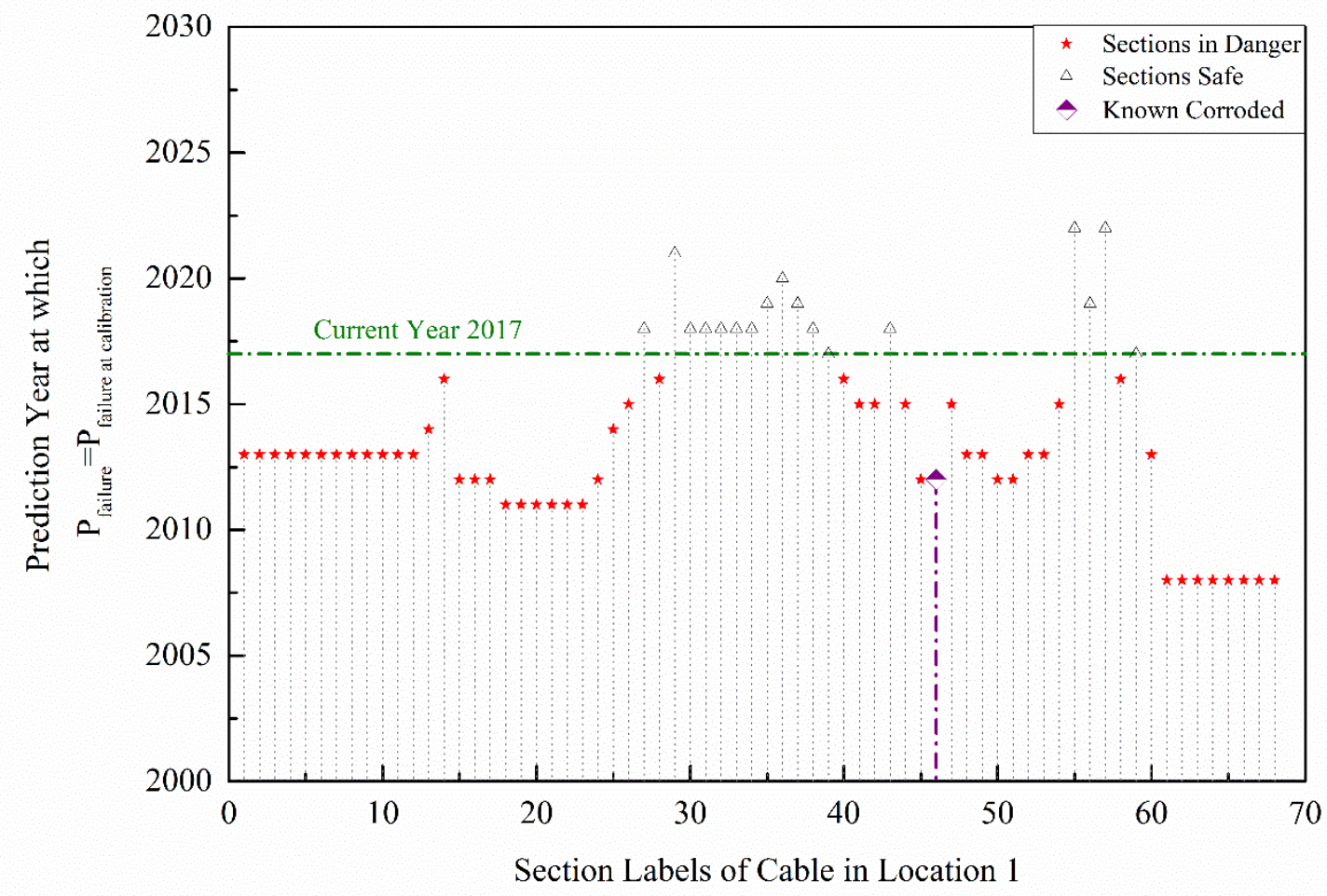

Figure 12: Validation of life prediction model by prediction year at which $P_{\text {failure }}=P_{\text {failure at calibration }}$ of different cable sections at Location 1 


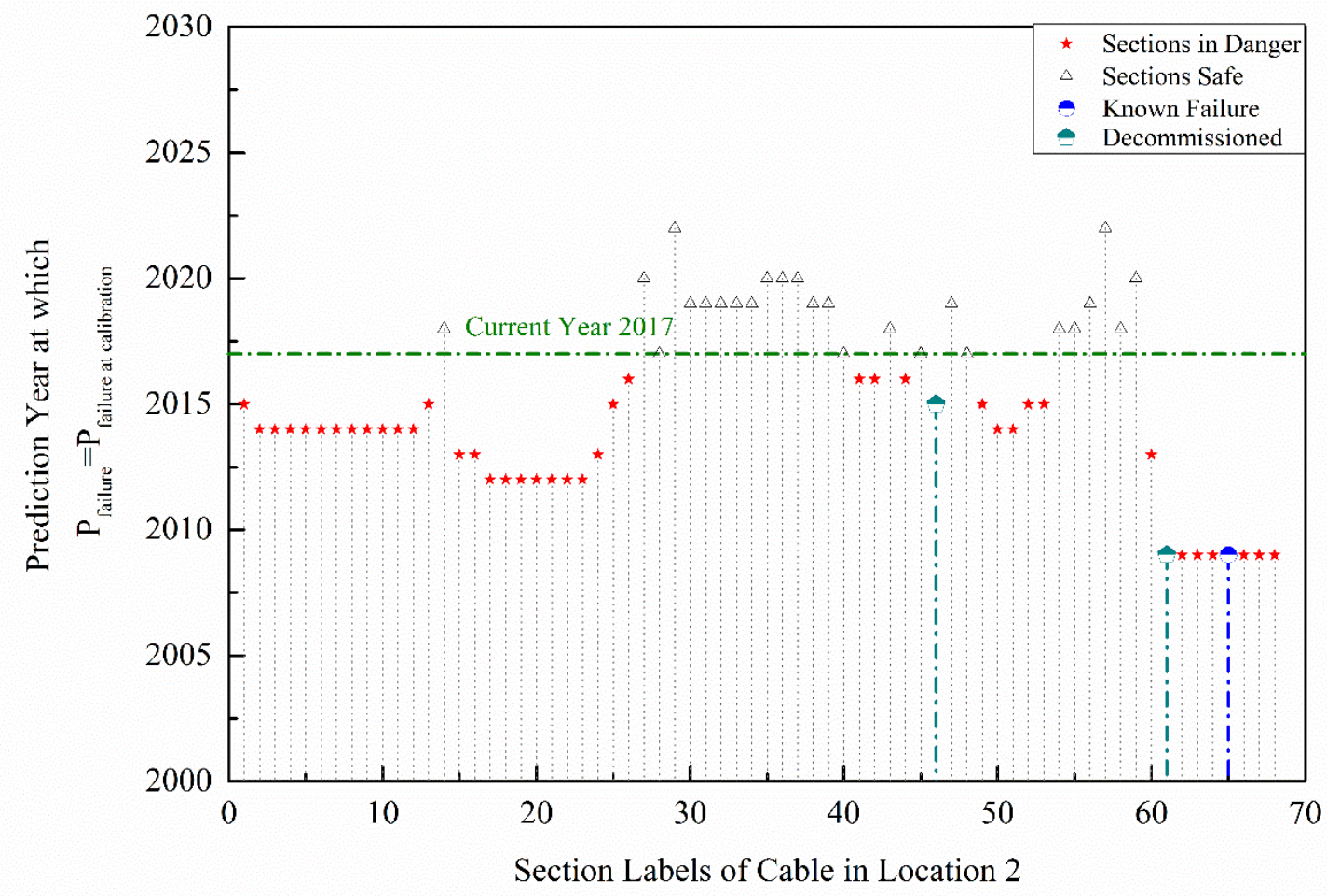

Figure 13: Validation of life prediction model by prediction year at which $P_{\text {failure }}=P_{\text {failure at calibration }}$ of different cable sections at Location 2 


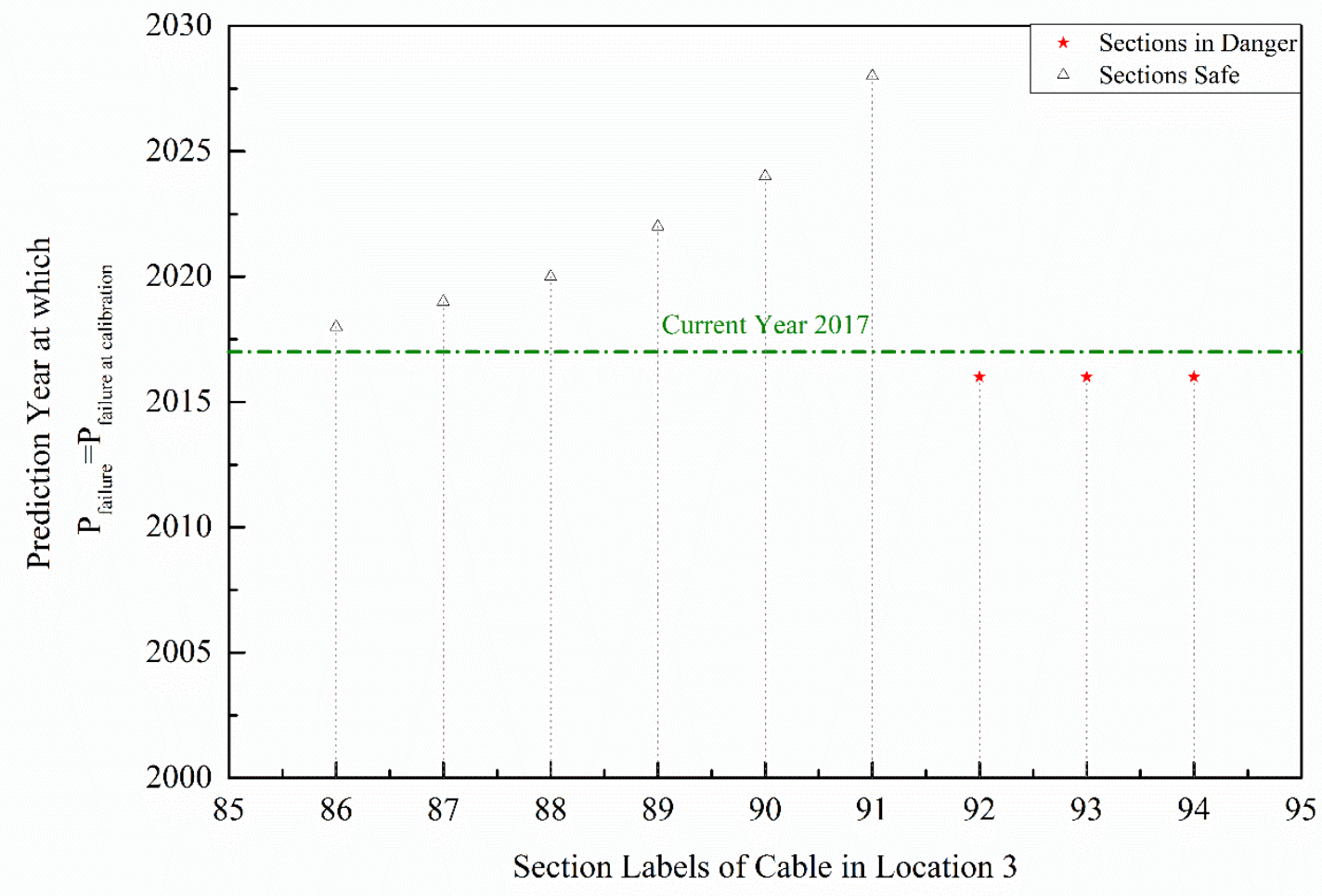

Figure 14: Validation of life prediction model by prediction year at which $P_{\text {failure }}=P_{\text {failure at calibration }}$ of different cable sections at Location 3 


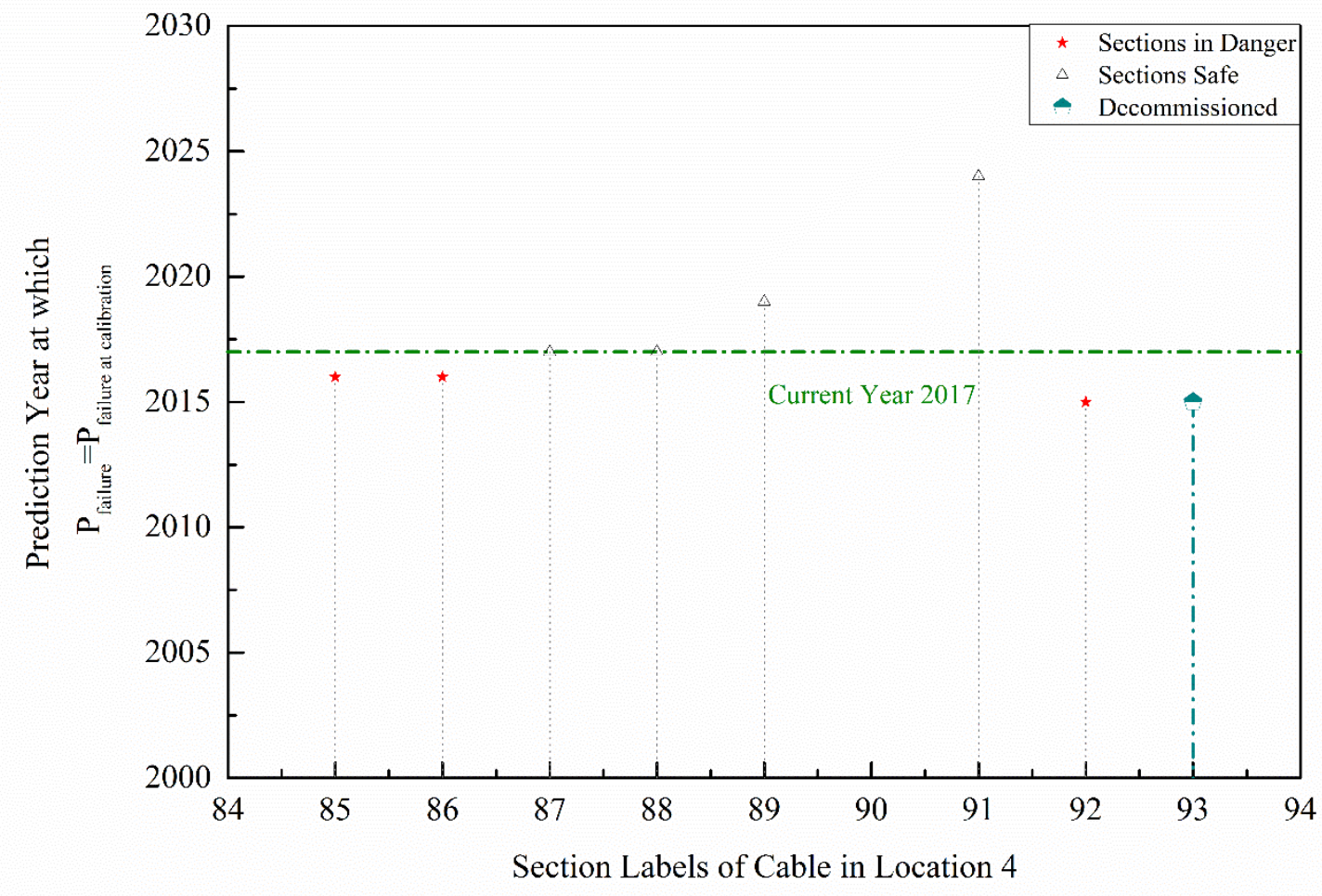

Figure 15: Validation of life prediction model by prediction year at which $P_{\text {failure }}=P_{\text {failure at calibration }}$ of different cable sections at Location 4 


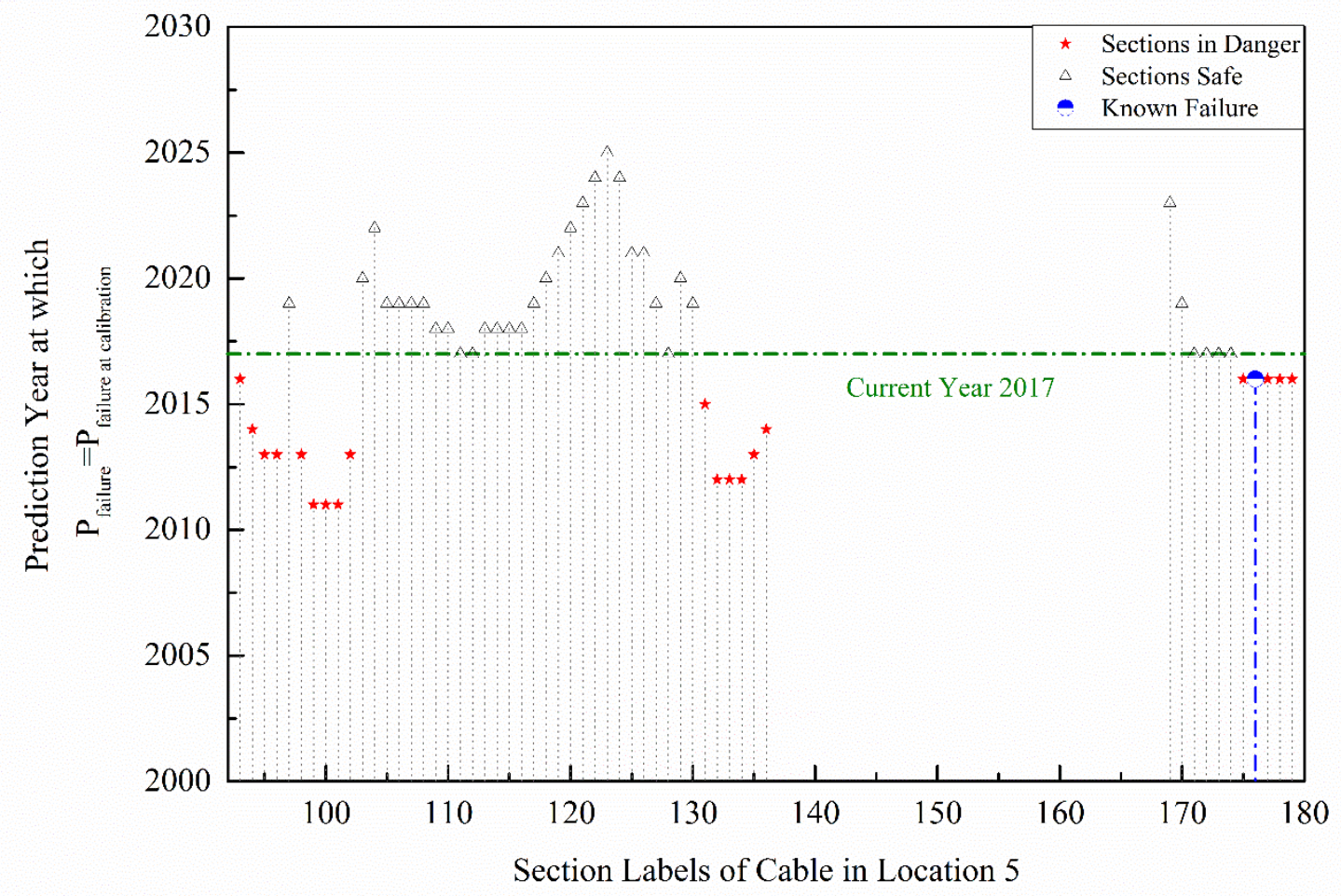

Figure 16: Validation of life prediction model by prediction year at which $P_{\text {failure }}=P_{\text {failure at calibration }}$ of different cable sections at Location 5 


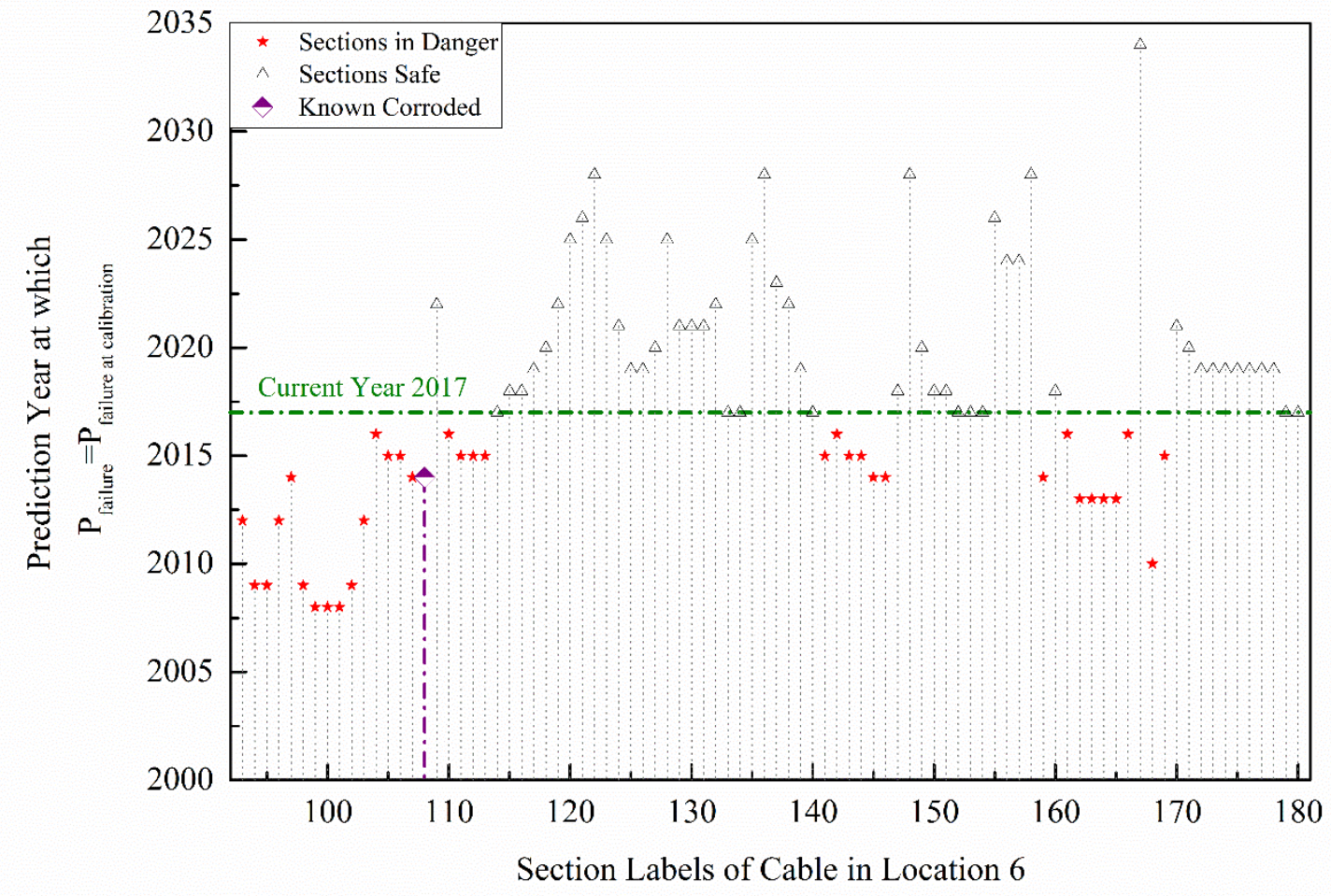

Figure 17: Validation of life prediction model by prediction year at which $P_{\text {failure }}=P_{\text {failure at calibration }}$ of different cable sections at Location 6 


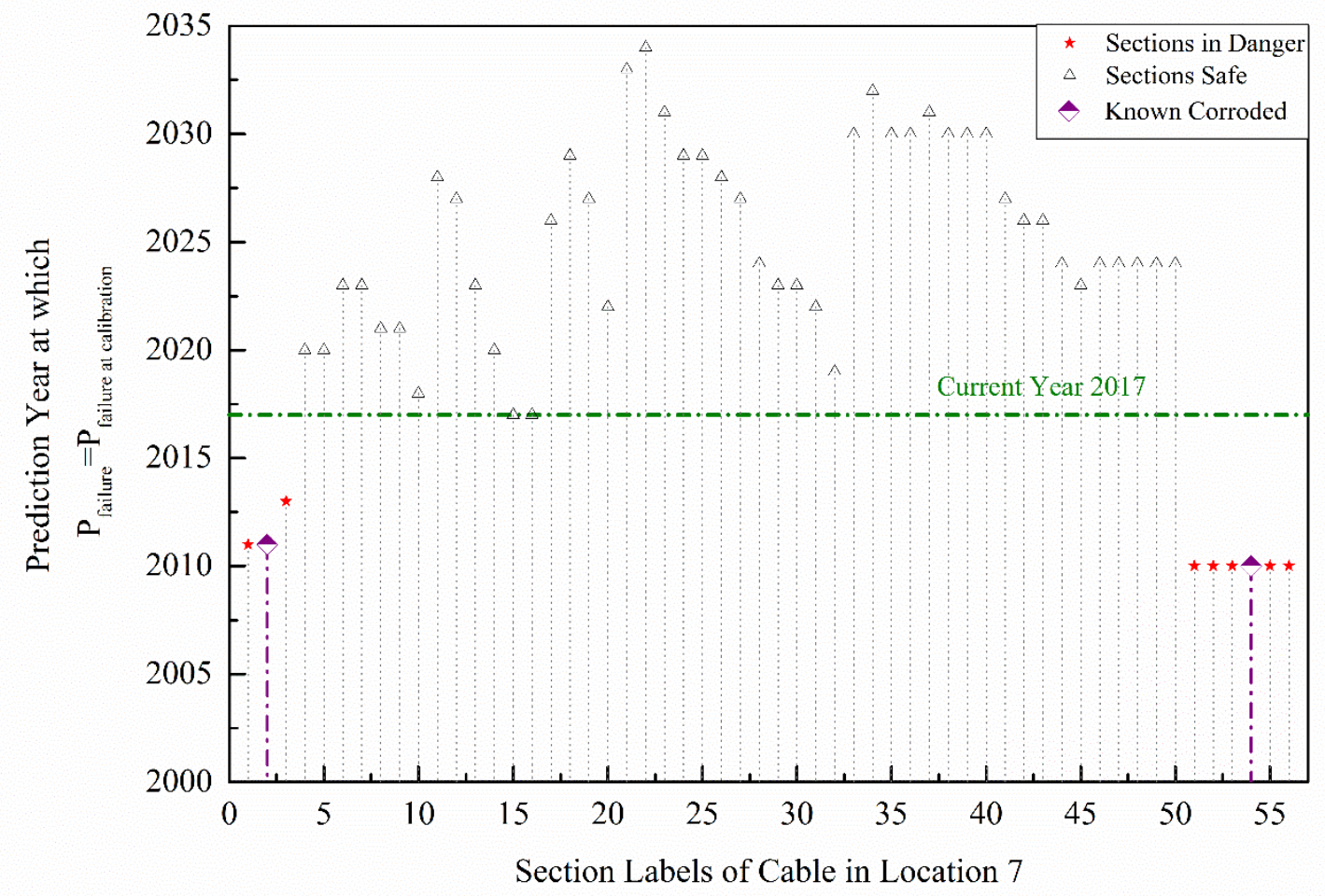

Figure 18: Validation of life prediction model by prediction year at which $P_{\text {failure }}=P_{\text {failure at calibration }}$ of different cable sections at Location 7 


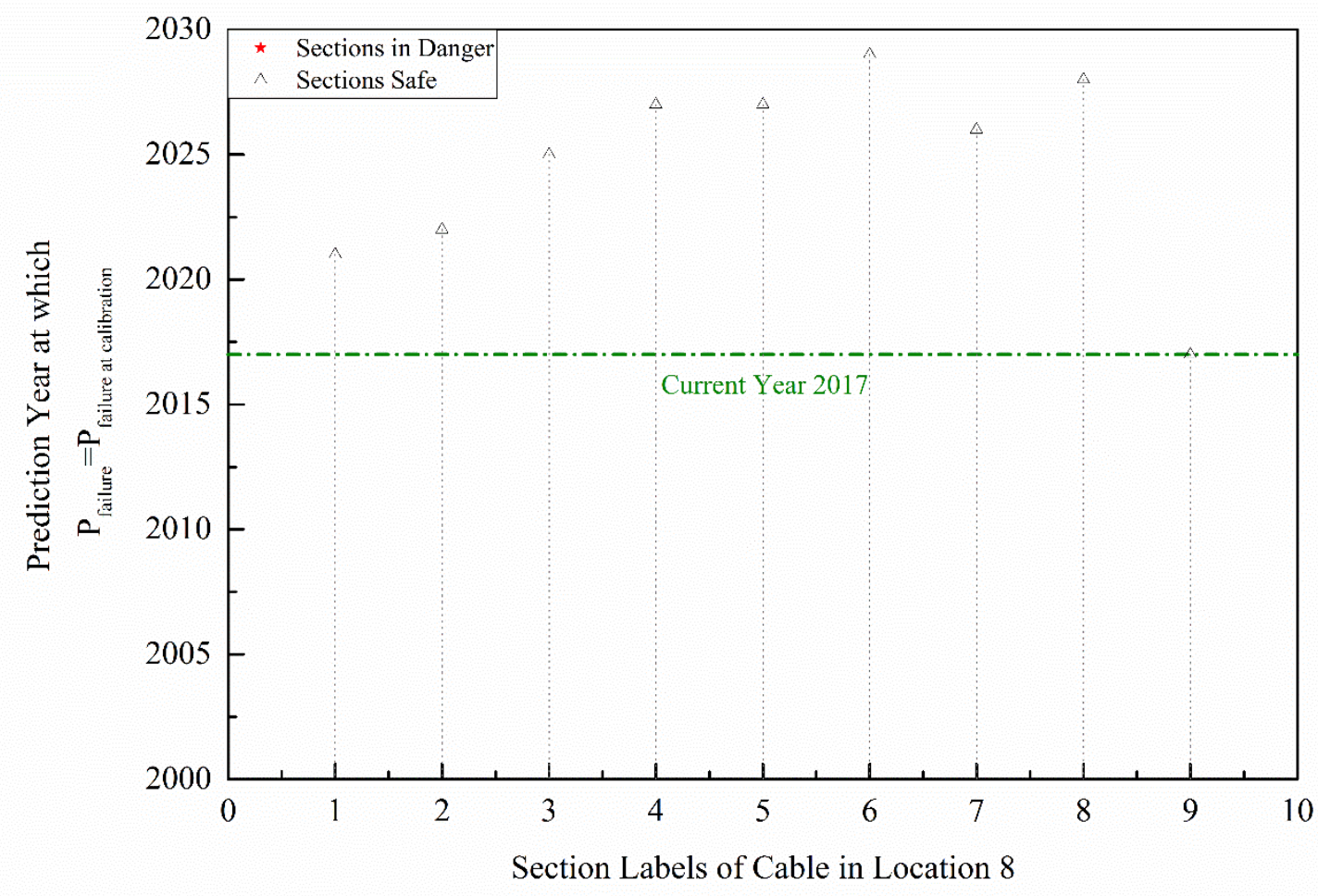

Figure 19: Validation of life prediction model by prediction year at which $P_{\text {failure }}=P_{\text {failure at calibration }}$ of different cable sections at Location 8 


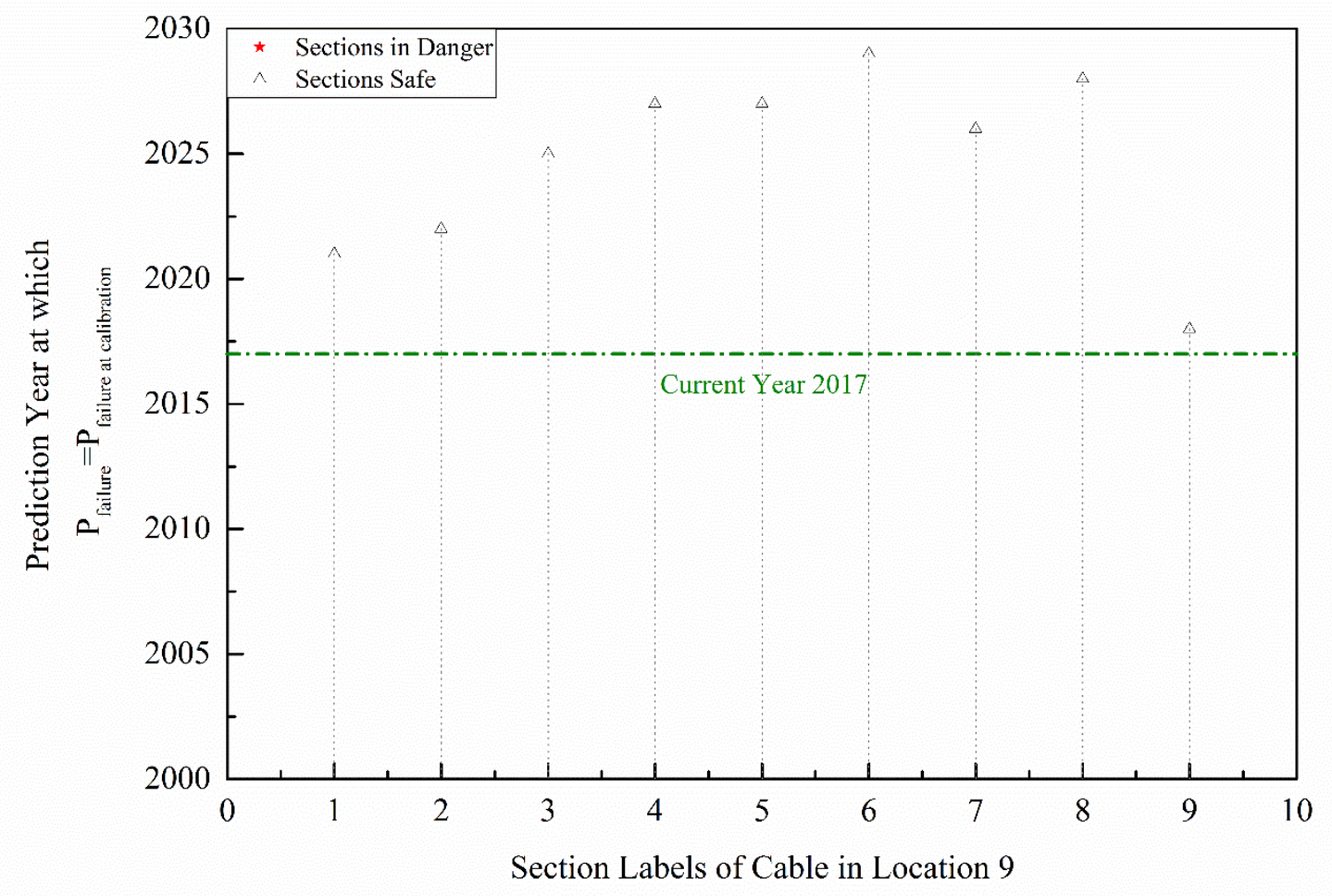

Figure 20: Validation of life prediction model by prediction year at which $P_{\text {failure }}=P_{\text {failure at calibration }}$ of different cable sections at Location 9 


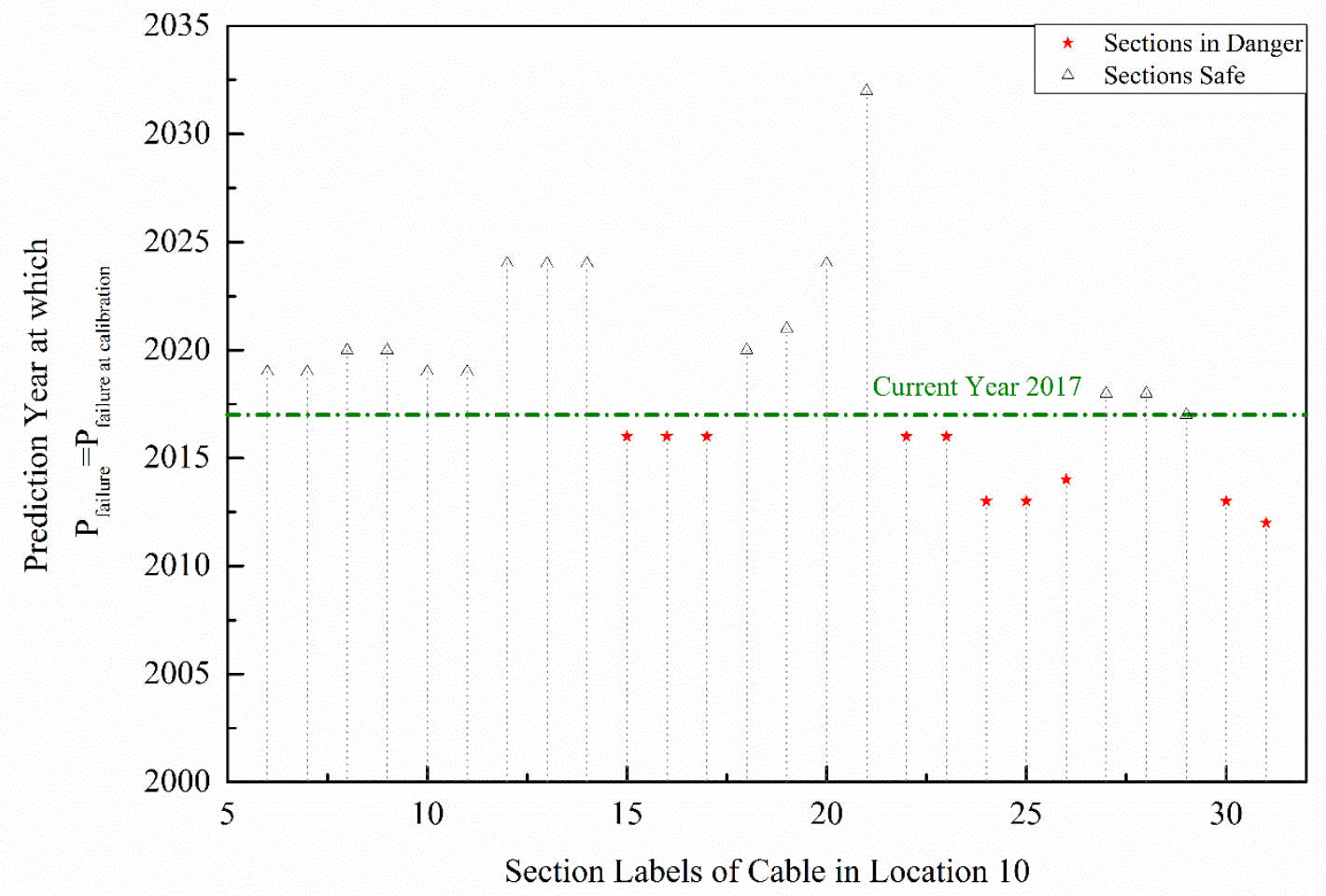

Figure 21: Validation of life prediction model by prediction year at which

$P_{\text {failure }}=P_{\text {failure at calibration }}$ of different cable sections at Location 10 